\title{
ARTÍCULOS
}

\section{DE ESPIONAJE Y CARTAS NÁUTICAS: EL IMPACTO DE AMÉRICA EN LA EUROPA DE PRINCIPIOS DEL SIGLO XVI.}

\author{
José María Moreno Madrid \\ Universiad Complutense de Madrid \\ imoren04@dhga.uhu.es
}

Resumen: La llegada de Cristóbal Colón a América en 1492 fue un acontecimiento que sacudió los cimientos del mundo occidental de la época. Una ingente cantidad de trabajos sobre esta cuestión se han centrado principalmente en el impacto que tuvo la llegada de los europeos al Nuevo Mundo, mientras que en mucha menor medida encontramos estudios que analicen el inmediato impacto americano en el Viejo Continente, especialmente en el campo de la historia cultural y del pensamiento. En este último ámbito menos trabajado se encuadraría esta investigación, cuyo objetivo es analizar algunos escenarios diplomáticos o de espionaje surgidos en la Europa de principios del siglo XVI a raíz de la primera empresa colombina. EI trasfondo de estos contactos es un mosaico de los principales intereses de la época, entre los que podemos destacar la obtención de informaciones para la construcción de obras cartográficas, ambiciones comerciales o alianzas que inviertan los equilibrios de poder.

Palabras clave: América, espionaje, cartografía, diplomacia, Portugal, Italia, Alberto Cantino.

Tittle: OF ESPIONAGEM AND NAUTICAL CHARTS: THE IMPACT OF AMERICA IN THE EUROPE OF THE BEGINNING OF THE XVI CENTURY.

Abstract: The arrival of Cristobal Columbus to America in 1492 is considered an important event that shook the foundations of the Western world. A great number of works and investigations about this topic have been focused in the arrival of Europeans to the American continent and its effect rather than on the analysis of the immediate impact of America on the Old World, especially in the field of cultural and intellectual history. This investigation will study that last theme mentioned, being its aim the analysis of the diplomatic scenarios and the collection of intelligence that arose during the XVI century in Europe as a result of the first voyage of Columbus. The historical context of these contacts is a mosaic of the main interests and intrigues of that time. We can highlight among them: obtaining of information to aid in the construction of cartographic works, the development of commercial ambitions, and the forging of alliances that inverted the balance of power.

Keywords: America, espionage, cartography, diplomacy, Portugal, Italy, Alberto Cantino.

Recibido: 05-07-2019

Aceptado: 11-07-2019

Cómo citar este artículo: MORENO MADRID, José María. De espionaje y cartas náuticas: el impacto de América en la Europa de principios del siglo XVI. Naveg@mérica. Revista electrónica editada por la Asociación Española de Americanistas [en línea]. 2019, n. 23. Disponible en: $<$ http://revistas.um.es/navegamerica>. [Consulta: Fecha de consulta]. ISSN 1989-211X. 


\section{Introducción}

El descubrimiento de América por Cristóbal Colón en 1492 para la Corona de Castilla supuso una auténtica revolución en un número nada desdeñable de mentes de la época. El marino genovés, ansioso por hallar un paso a las Indias más sencillo y directo que el que obligaba a atravesar plazas portuguesas y una ingente cantidad de leguas, convenció a los Reyes Católicos del espectacular beneficio que podría granjearles su empresa si llegaba a buen puerto. El puerto al que llegó no fue bueno, sino excepcional para la corona castellana. Pero en aquel momento era imposible atisbar siquiera la realidad a la que Colón le había abierto la puerta; para él, había logrado su objetivo, que era llegar a las Indias, y así lo transmitió a las instituciones a las que servía. En años sucesivos, múltiples viajes mediante, se fue percibiendo la magnitud del nuevo territorio descubierto, con gran asombro y deseo por parte de aquellos que vieron en el Nuevo Mundo un apetitoso pastel del que podrían cortar una provechosa porción. Pero era un pastel que tenía un grave problema: su inefabilidad.

A principios del siglo XVI sólo había una manera eficaz y respetada de hacer reales aquellos territorios en las mentes de quienes solo podían llegar a imaginarlas: a través de un mapa. Consecuentemente, la ciencia cartográfica experimentó un gran impulso, con especial incidencia en Castilla y Portugal, como resultado de su presencia en el Nuevo Mundo. Hay que matizar, no obstante, que en el caso luso la cartografía ya se había erigido en una ciencia fundamental muchos años antes de los descubrimientos americanos, ligada a su temprana expansión por los archipiélagos atlánticos y la línea de costa occidental africana. Castilla, por su parte, no había mirado al mar con especial interés hasta el gran periplo colombino de 1492, con la solitaria pero significativa excepción del archipiélago canario que había llegado a poner en peligro la paz ibérica en la década de 1420. Pero sí lo había hecho Aragón, que tenía en las aguas del Mediterráneo una potentísima red comercial que extendía sus tentáculos hasta los principales puertos italianos de la época. A medio camino, en el archipiélago balear, surgió la conocida como escuela mallorquina, que ya desde el siglo XIV se destacó como una de las grandes productoras de cartografía portulana con obras de la envergadura del Atlás Catalán (1375). De ella consiguió el Infante Don Henrique de Portugal los servicios de Jacome de Mallorca, que se desplazó a Portugal hacia 1427 para instruir en la ciencia cartográfica a los hombres de mar que allí se estaban formando. De este modo, la cartografía evolucionó paulatinamente durante los siglos XIV y XV en el ámbito ibérico, con focos de producción claramente marcados que, no obstante, interactuaban y presentaban similitudes reseñables.

En 1492 los Reyes Católicos desviaron su mirada al Nuevo Mundo, conscientes de haber encontrado allí un inesperado Jardín del Edén colonial que seguiría atrayendo de forma irresistible la mirada de sucesivos monarcas españoles en detrimento incluso de la metrópoli. La cartografía siguió la misma tendencia, y el Mediterráneo fue abandonando su condición eurocéntrica para cederle ese espacio a un nuevo y quimérico territorio que necesitaba ser reconocido, representado y controlado. En el caso portugués el proceso fue semejante, pero menos intenso, ya que Manuel I ya había encontrado en Asia su Edén colonial, y la corona lusa no 
desplazaría su mirada hacia el espacio carioca hasta bien entrado el siglo XVI, cuando el azúcar se erigió en uno de los productos estrella de los circuitos comerciales. Pero era territorio, era colonia, y estaba en la órbita de las pretensiones castellanas en América, por lo que reclamarlo y hacerse fuerte en él era sinónimo de reafirmar su papel en ese binomio iberoamericano que había resultado del Tratado de Tordesillas. Es menester añadir que ninguna ciencia podía ser tan eficaz como la cartografía para alegar la legitimidad portuguesa sobre la recién descubierta Terra dos Papagaios.

Si la cartografía siempre había tenido un valor incontestable como herramienta para el control y dominación nominal sobre un territorio, en este escenario multiplicaba espectacularmente sus prestaciones. Es por ello que asistimos a un crecimiento exponencial de redes de intereses entre los principales estados europeos inmersos en la actividad descubridora, ya sea directa o indirectamente.

El objetivo de este artículo es tratar los contactos que tuvieron lugar entre Italia, España y Portugal a principios del siglo XVI, tanto los puramente diplomáticos como aquellos otros de carácter más oscuro, rayanos en el espionaje y la traición. Así, el primer apartado del texto atiende a las relaciones entre Portugal y los Estados Italianos, prestando especial atención al conflictivo triángulo de intereses que se había constituido en torno al reino luso, Venecia y Ferrara. El segundo abordará el análisis de tres casos de espionaje en territorio portugués: Juan de la Cosa, Américo Vespucio y Angelo Trevisan, poniéndolos en relación con un cuarto caso de especial relevancia. Hablamos de la estancia de Alberto Cantino en Lisboa, sobre la que la historiografía de los Descubrimientos ha escrito prolijamente en las últimas décadas, pero descuidando aspectos muy interesantes sobre el contexto histórico del suceso $\mathrm{y}$, especialmente, olvidando una fuente primaria tan valiosa como es su correspondencia con el Duque de Ferrara. A través de un análisis minucioso de estos documentos se han podido extraer conclusiones novedosas y reflexiones que revisan ciertos dogmas que se habían establecido en torno a Alberto Cantino y su papel en Lisboa, pretendiendo con ello esclarecer algo más el complejo entramado de redes de intereses europeas resultantes del hallazgo del Nuevo Mundo.

\section{Relaciones de Portugal con los Estados Italianos}

El origen de las relaciones entre Portugal e Italia tuvo lugar bastante antes de lo que acostumbra a pensarse, partiendo de intereses primordialmente comerciales. En su estudio para el Centro de História de Além Mar (CHAM), Angelo Cattaneo sitúa el origen de estas relaciones a finales del siglo XIII e inicios del XIV, cuando la corona portuguesa consideró que podía obtener beneficio de las nuevas rutas mercantiles Génova/Pisa/Venecia - Londres/Brujas, otorgando beneficios fiscales a los navíos que hacían escala en puertos lusos, pudiendo así controlar los productos italianos que circulaban y colocando sus productos autóctonos en el circuito comercial ${ }^{1}$. Pero lo cierto es que los albores de esta relación italo-lusa se sitúan mucho más atrás en el tiempo; concretamente, a mediados del siglo XII, y ligados al florecimiento de

\footnotetext{
${ }^{1}$ CATTANEO, Angelo. Portugal e Cidades Italianas (s.XIV-XVI). Enciclopedia Virtual da Expansão Portuguesa [en línea]. Lisboa: CHAM, s.f. Disponible en $<$ http://eve.fcsh.unl.pt/content.php?printconceito=1191>.
} 
Venecia como gran potencia marítima. De hecho, las fuentes son claras respecto a la presencia de venecianos en Portugal y de portugueses en Venecia en el citado siglo XII y, por supuesto, en siglos posteriores ${ }^{2}$.

Según pasaban los años fue toda Italia la que siguió con atención los avatares de las empresas descubridoras portuguesas y españolas. Este interés quedó reflejado en un "riquísimo corpus de textos extremadamente variados (informaciones diplomáticas, cartas de viajantes y comerciantes, relatos de navegadores o de agentes económicos, obras de síntesis de carácter geográfico o cartográfico....”3. Claro que también desde Portugal supieron apreciarse las novedades que el mundo italiano ofrecía: diversas compañías mercantiles florentinas y genovesas ingresaban en sus filas estudiantes, miembros del clero o nobles portugueses, así como las universidades y los principales centros de cultura. Fue en Bolonia, Ferrara, Siena, Florencia, Pavia, Perugia y Pisa donde se formaron algunos de los hombres de época portugueses más destacados, promocionados por la Corona, prevaleciendo los estudios de derecho, teología y filosofía ${ }^{4}$.

\subsection{Venecia}

Si la llegada de Vasco da Gama a Calicut en 1498 fue motivo de gran alborozo en la corte lusa, en la Serenissima debió hacer saltar todas las alarmas. Venecia ya atravesaba momentos complicados ${ }^{5}$; si Portugal se hacía con el control de una nueva y eficiente ruta de comercio desde las Indias levantar cabeza sería una tarea mucho más compleja.

Manuel I, consciente del poderoso arma que tenía entre manos, y, sabedor del beneficio que de él podía extraer, decidió explotarlo de forma inteligente: mientras que las especias y drogas que llegaban a Venecia eran vendidas a un precio mucho más elevado respecto al que eran compradas, con unos tremendos impuestos en el transporte (60-100\%), desde Portugal se decidió que esos impuestos se reducirían al $29 \%{ }^{6}$. Es menester decir que Venecia sintió de lleno el impacto de estas acciones, percibiendo que los habituales compradores de especias y productos orientales en la ciudad italiana podían desplazar su foco de acción a Portugal ${ }^{7}$, por lo que desplegó una red de información sobre el reino luso para estar siempre al tanto de lo que acontecía en torno a su nuevo e intimidante competidor ${ }^{8}$. La vía diplomática se postulaba como la única opción plausible para poner freno a este floreciente monopolio de comercio de especierías orientales que estaba gestando Portugal; la

\footnotetext{
${ }^{2}$ MARQUÉS DE OLIVEIRA, Julieta Teixeira. Veneza e Portugal no século XVI. Vol. I. Lisboa: Biblioteca Nacional de Portugal, 1994, p.75 y pp.78-79.

${ }^{3}$ RADULET, Carmen M. Os descobrimentos portugueses e a ltália. Lisboa: Vega, 1991, p.39.

${ }^{4}$ CATTANEO, Angelo. Portugal e Cidades Italianas. Op. cit.

${ }^{5}$ Para un análisis más completo de los problemas que atravesaba Venecia a inicios del siglo XVI véase: LÓPEZ FORERO, Abel Ignacio. Europa en la época del descubrimiento: comercio y expansión ibérica hacia ultramar, 1450-1550. Bogotá: Planeta Colombiana Editorial, 1998, pp.133-40.

${ }^{6}$ Los efectos de la flamante ruta comercial lusa se dejaron sentir hasta tal punto que el valor de las especierías en la ciudad italiana variaba en función del contenido de las carabelas que llegaban a Lisboa, venidas de Calicut. En: MARQUÉS DE OLIVEIRA. Veneza e Portugal no século XVI. Op. cit., pp.95-96.

7 Ibídem, pp.92-94.

${ }^{8}$ Ibídem.
} 
distancia y el temor a una reacción ibérica eran obstáculos que la Serenissima no podía sortear? ${ }^{9}$.

En estas circunstancias, la República de Venecia decidió enviar un embajador de urgencia a Lisboa en 1501: Piero Pasqualigo ${ }^{10}$. La premisa de este envío fue la petición de ayuda al rey de Portugal para luchar contra los turcos ${ }^{11}$, que estaban amenazando algunos dominios venecianos en la zona del Peloponeso. Denegada su petitoria por el monarca, Pasqualigo permaneció en Lisboa y llevó a cabo algunas indagaciones sobre las medidas tomadas por Don Manuel para dinamizar el comercio con las Indias. Parece que sus pesquisas llegaron a buen puerto, escribiendo a la Serenissima a finales de 1501 e informando del envío de seis navíos armados a Calicut durante los tres últimos años, pretendiendo con ello fortalecer su presencia en la zona y afianzar el monopolio de las especias ${ }^{12}$.

No se sabe mucho más de las actividades de Pasqualigo por su propia pluma, pero si por la pluma de otro célebre italiano y último responsable del estudio que aquí abordamos: Alberto Cantino. En la carta fechada a día 30 de enero de 1501, Cantino relata al Duque de Ferrara el homenaje celebrado en la catedral de Lisboa para honrar a Vasco de Gama por sus proezas. En las últimas líneas del texto, refiere lo siguiente: "Hecho esto, [Vasco de Gama] se encontró besando la mano del rey, al igual que todos los nobles y caballeros, disfrutando [así] [el Rey] de los honores y dignidades que añadió a su corona, y el embajador de Venecia hizo lo mismo" 13 .

Sabemos así que Pasqualigo ya había llegado a Lisboa a inicios de 1501 y que, del mismo modo que Cantino, tenía acceso y presencia en los acontecimientos más destacados de la capital lusa. No obstante, tras su fracaso en las negociaciones con Don Manuel, y, al parecer, sin acceso a más información relevante que obtener, Pasqualigo decide abandonar Portugal y se dirige a la corte española, donde continuó con su rol de embajador veneciano. Allí recibió una interesante carta de

\footnotetext{
${ }^{9}$ Ibídem, pp.104-5. Sobre esta cuestión es también interesante leer: SOLER, Isabel. El sueño del Rey. Barcelona: Acantilado, 2015, pp.105-6.

${ }^{10} \mathrm{~N}$. del A.: En cierto sentido, podría incluirse a Piero Pasqualigo en el siguiente apartado, ya que su presencia en la capital lusa podría estar ligada también a actividades de espionaje, tal y como reflejan las cartas enviadas a Venecia y que serán tratadas en esta sección; no obstante, parece que en el caso de Pasqualigo no podemos hablar de un espionaje cartográfico, sino relacionado con cuestiones comerciales y político, por lo que el análisis de sus actividades será tratado en esta parte. Para más información sobre la figura de Pasqualigo véase: BROWN, Rawdon (ed.). Calendar of State Papers and Manuscripts Relating, to English Affairs, Existing in the Archives and Collections of Venice: And in Other Libraries of Northern Italy. London: H. M. Stationery office, 1867, p. 195.; GRAVES, Michael A. R. Henry VIII: A Study in Kingship. Hong Kong: Pearson Education, 2003, p. 41.; FURTADO, Peter. History's Daybook: A History of the World in 366 Quotations. Londres: Atlantic Books Ltd, 2012.

${ }^{11}$ Ante esta petición, Don Manuel despacha a Pasqualigo informándole de que algunas de las carabelas que integraron la flota comandada por Gonzalo de Córdoba para la defensa de Modón eran de su propiedad. En: GIUSTINIANI, Sebastiano. Four Years at the Court of Henry VIII. London: Imp. Smith, Elder \& Co., 1854, p.82.

${ }^{12}$ Ibídem.

${ }^{13}$ CANTINO, Alberto; HARRISE, Henry y ALMEIDA, Frederico de (eds). Document inédit concernant Vasco da Gama: relation adressée a Hercule d'Este, Duc de Ferrare. Paris: 1889, p. 21.
} 
Giovanni Francesco de la Faitada ${ }^{14}$, su sucesor en Lisboa, fechada a día 17 de octubre de 1503 en la que se relatan los movimientos llevados a cabo por Don Manuel en lo que a la ruta de Indias se refiere.

Así pues, podemos observar como las relaciones entre Venecia y Portugal a inicios del siglo XVI no eran todo lo fluidas que hubieran deseado ambas potencias $^{15}$. Sin embargo, pese a las desavenencias políticas, y como se ha mencionado al inicio de este apartado, el intercambio cultural fue una enriquecedora constante que se extendió durante más de dos siglos.

\subsection{Ferrara}

Si atendemos a los estudios llevados a cabo sobre este periodo o, más concretamente, sobre el Planisferio Anónimo de 1502 o Planisferio de Cantino, pocos o ninguno encontramos que hagan referencia a una relación entre Portugal y Ferrara antes del envío de Alberto Cantino. De hecho, podríamos llegar a pensar que no existió ninguna, pero tal circunstancia se antoja difícil cuando hablamos de Historia; consecuentemente, durante el S.XV existieron contactos entre las cortes de ambos centros de poder que a largo plazo podrían haber influenciado en las circunstancias en las que fue dibujado el Planisferio Anónimo.

El primer contacto entre Portugal y Ferrara en el S.XV del que tenemos noticias es el viaje que realizo el infante Don Pedro por tierras europeas, antes de convertirse en regente de Portugal (1439-1448). Se trataba de un hombre con gran inquietud intelectual y cultural, sobre todo en lo que concernía al ámbito de las humanidades. Se decía de él que andou as sete partidas do mundo ${ }^{16}$, con motivo de su viaje, que comenzó en $1425^{17}$. Partió de la Villa de Barcelós, acudió a Valladolid para presentarse ante el rey Castilla, navegó hasta Venecia, partió hacia Chipre para hacer lo propio ante el Gran Turco de la ciudad de Mandua y después se dirigió a Babilonia, Tierra Santa y Jerusalén; desde allí puso rumbo a la sierra de Armenia (donde estaba el Arca de Noe), Arabia, Monte Sinaí, la tierra de las Amazonas de la Ciudad de Sonterra, Cananea y a los territorios del Preste João. Finalmente, regresó a Castilla ${ }^{18}$.

\footnotetext{
${ }^{14}$ También reseñable es la Carta sobre Brasil que envía el 26 de junio de 1501 a Domenico Pisani, por entonces embajador veneciano en Madrid, en la que el territorio latinoamericano aparece referido como tierra de papagallos. En: ESTEVES PINHEIRO, José Julio. Carta do Achamento do Brasil de Pêro Vaz de Caminha. ESEG Investigaçao. 2008, n. 7, p. 51.

${ }^{15} \mathrm{~N}$. del A.: Pese a ello, y como se verá más adelante cuando se analicen las cartas enviadas por Cantino al duque de Ferrara, el embajador veneciano tuvo acceso a los entresijos de la corte portuguesa, lo que queda demostrado con su cercanía al monarca y su presencia en actos y lugares de gran prestigio. Pese a la compleja situación que ligaba ambas potencias, el rey luso concedió grandes privilegios a Pasqualigo, confiando quizá en la imposibilidad de que consiguiera alguna información comprometida; además, el protocolo diplomático de la época era algo que difícilmente podía ser vadeable sin consecuencia alguna, de lo que Don Manuel era plenamente consciente.

${ }^{16}$ SANTO ESTEVÃO, Gomes de. Livro do infante Dom Pedro de Portugal, o qual andou as sete partidas do mundo. Lisboa: Imp. de Francisco Borges de Sousa, 1767, p. 1.

${ }_{17}$ PIEL, Joseph M. Livro dos Oficios de Marco Tullio Ciceram, o qual Tornou em Linguagem o Infante D. Pedro, Duque de Coimbra. Coimbra: Universidade de Coimbra, 1948, p. 14.

${ }_{18}$ Títulos extraídos de: SANTO ESTEVÃO, Livro do infante Dom Pedro de Portugal. Op. cit. Para conocer el relato completo de los viajes léase el resto de la edición.
} 
En su recorrido por Italia, se detuvo también en Florencia, Bolonia y por supuesto Ferrara ${ }^{19}$. Podríamos, por tanto, establecer aquí el primer contacto oficial entre ambos territorios, destacando que fue llevado a cabo por un infante portugués; a priori, el encuentro no debió resultar demasiado fructífero ${ }^{20}$, o, al menos, no se le otorgó una excesiva atención en los relatos y fuentes.

El segundo nexo de unión luso-ferrarense lleva también nombre propio: Gomes Eanes $^{21}$. Como figura fuerte del rey de Portugal en el Concilio de Basilea, Eanes tendría que haberse desplazado junto con el papa a Ferrara, donde fue trasladado el sínodo. Pero no lo hizo, reincorporándose a la corte papal el 22 de enero de 1439, cuando ya se había hecho efectivo el traslado a Florencia ${ }^{22}$. No obstante, no podía desentenderse de la defensa de los intereses portugueses (fundamentalmente el derecho sobre las Islas Canarias y la expansión por el litoral africano), por lo que envió a su maestro Ludovico Barbo $^{23}$, con el cual probablemente intercambiaría todas las informaciones relativas a lo acontecido en Ferrara. Hablamos por tanto de un contacto secundario, pues Eanes evitó acudir a la corte estense delegando en Barbo.

Sin embargo, dentro de este contacto secundario encontramos una serie de documentos de lo más interesantes para seguir ahondando en la presencia portuguesa en Ferrara durante el siglo XV. Nos referimos a una sucesión de epístolas ${ }^{24}$ fechadas entre 1427 y 1438 que tienen como punto en común el nombre de su destinatario: nuevamente, Gomes Eanes. Estos documentos nos permiten colocar sobre el mapa a Álvaro de Almeida, un nuevo intermediario portugués en la

${ }^{19}$ ROGERS, Francis M. y SANTO ESTEVÃO, Gomes de. The Travels of the Infante Dom Pedro of Portugal. Harvard: Harvard University Press, 1961, p. 50.

${ }^{20} \mathrm{~N}$. del A.: Cuando el infante llegó a Ferrara estaba ya asentado Nicolás III d’Este como gobernante. Lo más probable es que recibiera una cálida acogida, pues en ese primer tercio del S.XV el dirigente estense se había cuidado bien de convertir su corte en un centro de recepción de cultura e influencia renacentista; por ello, la visita de un infante de una corte lejana sería motivo de alborozo. Para saber más sobre el patrocinio de las Artes y Humanidades llevado a cabo por Nicolás III veáse: PADE, Marianne; PETERSEN, Lene Waage y QUARTA, Daniela. Court of Ferrara \& its patronage. Copenhague: Museum Tusculanum Press, 1990, pp. 71-90.

${ }_{21}$ Gomes Eanes (c.1383-1459). Benedictino portugués que hizo posible la restauración de Santa María di Firenze, entre los años de 1419 y 1439. En ese año fue nombrado General de la Orden Camaldolese, hasta 1441, y de esta fecha hasta la de su muerte ejerció como prior del monasterio agustiniano de Santa Cruz, en Coimbra. Además, fue miembro del Consejo Real de Duarte I y Afonso V, así como el legado papal de Portugal entre 1435 y 1437. Como tal, participó activamente en numerosos acontecimientos eclesiásticos destacados, como las últimas etapas del Concilio de Basilea/Ferrara/Florencia, apoyando a Eugenio IV y como agente de los reyes lusos. Destaca también su labor humanista en la ciudad de Florencia. En: ELBL, Ivana y ELBL, Martin Malcolm. The Private Archive (Carteggio) of Abbot Dom Fr. Gomes Eanes (Badia Di Firenze) -- An Analytical Catalogue, with Commentary, of Codex Ashburnham 1792 (Biblioteca Medicea Laurenziana, Florence): Part One. Portuguese Studies Review. 2014, vol. 21, p. 21.

22 Ibídem, pp.26-27.

${ }^{23}$ Véase: TASSI, Ildefonso. Ludovico Barbo (1381-1443). Roma: Ed. di Storia e Letteratura, 1952. Para información concreta sobre su labor en el Concilio de Basilea/Ferrara/Florencia véase las páginas 94-97.

${ }^{24} \mathrm{~N}$. del. A.: Las citadas epístolas son documentos de archivo que no han sido publicados aún, por lo que nos vemos limitados para analizarlas con todo lujo de detalles. Las informaciones generales sobre las mismas pueden ser consultadas en: En: ELBL, Ivana y ELBL, Martin Malcolm. The Private Archive (Carteggio)... Op. cit. 
ciudad de Ferrara. Sabemos de él que: "[...]Arrived in Ferrara on 7 Jun [de 1437]. Carries several letters from the King of Portugal and much other correspondence. Batch includes a missive from the Prior of S. Estevão (de Alfama (Lisboa))"25.

Esta información está contenida en una misiva enviada a desde Ferrara a Florencia a día 9 de junio de 1437, siendo el destinatario de la misma Gomes Eanes. La idea de que un emisario portugués llegase a Ferrara cargando una cantidad reseñable de cartas y otros escritos firmados por el rey portugués -entre otrosresulta de lo más interesante. No tanto por el contenido de las mismas -que seguramente estaría monopolizado por las cuestiones religiosas derivadas del Concilio-, sino por la idea de que ya en la década de 1430 se había tendido entre Portugal y Ferrara un puente comunicativo más o menos estable.

Pero poco después, probablemente en agosto de ese mismo año, Almeida vuelve a dirigirse a Eanes, esta vez sin aclarar desde donde (Ferrara o Bolonia), incluyendo el escrito la siguiente información:

Álvaro de Almeida requests instructions and hopes to secure further favours from Dom. Fr. Gomes Eanes. Reports the rumoured forthcoming arrival in Bologna or Ferrara of Hughes Lancelot de Lusignan, and also news concerning the Infante D. Henrique and the Tangier expedition (brought by an Aragonese traveller and base don a letter apparently received by the King of Navarre). Dom Fr. Gomes Eanes is attempting to sell of to the Curia some of the Badia's supernumerary mules ${ }^{26}$.

De esta carta podemos extraer la idea de que a Eanes no le bastaba con la presencia de Ludovico Barbo en Ferrara, sino que aprovechando la llegada de Almeida (o quizá requerida por él) le emplea para obtener informaciones adicionales ${ }^{27}$ sobre lo que está ocurriendo en la villa estense. Podemos hablar así de una especie de agente de Eanes en Ferrara que no está tanto espiando los asuntos que atañen a la propia ciudad -lo cual resultaría de sumo interés para nuestro estudio-, sino los relativos al Concilio o a los avatares portugueses que tienen lugar más allá de las fronteras italianas.

Finalmente, debemos dar un salto en el tiempo obligados por la escasez -o prácticamente vacío- de fuentes documentales. Son muy pocos los datos que tenemos sobre el último contacto oficial registrado entre Portugal y Ferrara del S.XV; consecuentemente, son muy pocos también los títulos que incluyen un estudio sobre esta cuestión. En «Borso D'Este and the Arthurian Legend: a reconsideration of the Hall of the months in the Palazzo Schifanoia, Ferrara» Kathryn Amanda Sullivan escribe lo siguiente acerca de esta cuestión: "In 1469, the grandson of Alfonso V, King of Portugal, explicitly requested entry into the palazzo during his visit to Ferrara" 28 .

\footnotetext{
${ }^{25}$ Ibídem, p.122.

${ }^{26}$ Ibídem, pp.127-28.

${ }^{27} \mathrm{~N}$. del A.: De hecho, la primera línea parece referirse a una clara relación de patronazgo: Entrega de ordenes [Request instructions] a cambio de obtención de favores [and hopes to secure further favours from Dom. Fr. Gomes Eanes].

${ }^{28}$ SULLIVAN, Kathryn Amanda. Borso D'Este and the Arthurian Legend: a reconsideration of the Hall of the months in the Palazzo Schifanoia, Ferrara. Birmingham: University of Alabama Press, 2009, p.
} 
Por su parte, Tomas Tuohy refiere lo siguiente: "[...] The visit of the prince of Portugal in 1470 for which Belriguardo was prepared with tapezaria. In the event Don Alfonso of Portugal had confused Belriguardo with Belfiore which was not furnished and he had to be content with admiring some tapestries specially hung for his perusal in the Corte" 29 .

A nuestro parecer, los datos aportados por Sullivan son de difícil aceptación, pues el nieto de Afonso V, el futuro Manuel de Portugal, nació el mismo año de 1469, dificultando tal visita a Ferrara. Por su parte, un viaje en 1470 del por entonces monarca portugués si tendría más sentido, si bien es cierto que en el verano del año siguiente se encontraría luchando en África para consolidar su dominio de Arzila. No obstante, seis años habían pasado desde la campaña de Tánger, y nada impedía al rey llevar a cabo tal viaje, por lo que la fecha nos parece perfectamente factible. La aceptación de la misma nos sitúa en un escenario interesante: desde la llegada de Dom Pedro a la corte estense se mantiene durante gran parte del S.XV una conexión entre ambos centros de poder casi permanente ${ }^{30}$, la cual no podemos seguir durante todo el desarrollo, pero si marcar los momentos de contacto gracias a los registros que nos han llegado. De nuevo, desde esta última visita al encargo del Planisferio nos veremos obligados a saltar en el tiempo tres décadas, ya que no tenemos informaciones de posteriores tomas de contacto; quizá porque no nos han llegado, o quizá porque no se produjeron, estando Portugal envuelta en conflictos con Castilla y Ferrara en guerra con Venecia.

Concluyendo, queremos cerrar esta sección resaltando que Portugal y Ferrara distaron mucho de ser dos desconocidos durante el siglo XV, y que la magnitud de una visita real parece apuntar a que en los albores del siglo XVI el vínculo podría haberse mantenido o, incluso, reforzado.

\section{Los límites de la política do sigilo: las fugas}

Con el avance de la circunnavegación de África, y, sobre todo, con el retorno de Vasco da Gama, Lisboa se convirtió en el destino de numerosos agentes enviados por sus estados o patrones para hacerse con las noticias que de las nuevas tierras llegaban a la capital lusa. Para estos agentes no había soporte más idóneo que la cartografía para retener las informaciones que pretendían trasladar a sus señores, pues, para hacer real un territorio había que dibujarlo en un mapa. No es de extrañar por tanto que muchos de ellos concentraran sus esfuerzos en sacar de Lisboa alguna carta náutica, infracción que no fue duramente castigada por el monarca portugués Manuel I hasta el 13 de septiembre de $1504^{31}$, cuando decretó que: "[...] El depositario oficial no debía, bajo pena de muerte, dejar ver los "roteiros", los

2. Extraído, a su vez, de: ROSENBERG, Charles M. 'Per il bene di...nostra cipta': Borso d'Este and the Certosa of Ferrara. Renaissance Quarterly. 1976, vol. 29, n. 3, p. 340.

${ }_{29}$ TUOHY, Thomas. Herculean Ferrara: Ercole D'Este (1471-1505) and the Invention of a Ducal Capital. Cambridge: Cambridge University Press, 2002, p. 220.

${ }^{30} \mathrm{~N}$. del A.: Nos es imposible saberlo debido a los vacíos de documentación, pero el hecho de que el monarca portugués se digne a efectuar una visita en persona a la villa algo más de treinta años después de la presencia de Almeida nos resulta bastante concluyente.

${ }_{31}$ GARCí́A COBO, Pedro Luis [et al]. Juan de la Cosa, santoñés universal. Santoña: Excmo. Ayuntamiento de Santoña, Concejalía de Cultura y Deporte, 2000, p. 62. 
diarios de navegación, y mucho menos las cartas marinas. Antes, correspondía al Piloto Mayor la tarea de "eliminar de las obras cartográficas los descubrimientos nuevos que conviniese mantener secretos, y se le concedía privilegio real exclusivo de proveer cartas autorizadas, hechas conforme al tipo aprobado ${ }^{32,}$.

Así pues, a lo largo del primer lustro del siglo XVI fueron muchos los que se infiltraron en Lisboa afanándose por obtener informaciones que merecieran la pena. Debido, evidentemente, a la clandestinidad de sus operaciones, son escasos los registros de sus actividades que se han conservado. Se presentan pues, en este apartado, algunas de las incursiones más relevantes, aquellas que pusieron en evidencia las insalvables brechas a las que se enfrentaba la política del sigilo.

\subsection{Juan de la Cosa}

El viaje realizado a Lisboa en 1503 es un aspecto de la vida del marino santoñés sobre el que no se ha indagado mucho en la historiografía moderna o contemporánea, por lo que es imposible disponer de todos los datos y fuentes que querríamos y que serían necesarios para entender mejor este suceso.

En cualquier caso, parece que la mayoría de los autores estudiosos de la cuestión coinciden en cuanto a los aspectos cronológicos del viaje. Navarrete refiere el acontecimiento de la siguiente manera:

Sin embargo, cuando a mediados del año 1503 andaban los oficiales de la contratación en conciertos con Juan de la Cosa sobre su viage con tres navíos para ir a descubrir por la parte de Urabá, llegó correo a la corte el 13 de Julio con la noticia de que cuatro navíos de Portugal habían ido a la tierra que descubrió Bastidas y traído de allí esclavos, indios y varias producciones. Para asegurarse de esto fue la Cosa enviado a Lisboa, donde le prendieron; pero logró pronto su libertad, pues en septiembre pasó a la corte que estaba en Segovia, e informó a la Reina haber sido cierto aquel viage, y aún otro que habían repetido en este año, presentándola al mismo tiempo dos cartas hidrográficas de las Indias ${ }^{33}$.

Conservamos también algunos de los asientos de la época, redactados por Sancho de Matienzo -Tesorero Real- que recogen información importante sobre el viaje: "A Juan de la Cosa en 22 días de Agosto deste año, diez ducados de oro para

\footnotetext{
32 LEVILLIER, Roberto. América la Bien Llamada. Michigan: Editorial G. Kraft, 1948, p. 20. El secretismo que acompañó al avance de la náutica se mantuvo durante el siglo XVI, aunque de forma cada vez más laxa hasta alcanzar el periodo de la unión de coronas. Prueba de ello es el siguiente extracto del Libro de las Longitudes... de Alonso de Santa Cruz: "[...] No me satisfaciera si no hablara con $\mathrm{D}$. Juan de Castro, caballero muy docto y muy curioso que había ido a la India muchas veces y había hecho la discreción de ella de punto muy grande, poniendo por escrito y en pintura los puertos, ríos y baxos que a la entrada y dentro de ellos están, con las historias de las cosas notables de las tierras y lugares que en ellas están [...], de los cuales libros me dio el traslado conque no los mostrase a ninguna persona de Portugal para que hiciese de manera que la memoria de obras tan insignes y de tanta curiosidad no se perdiese..." En: SANTA CRUZ, Alonso de. Libro de las Longitudes y manera que hasta agora se ha tenido en el arte de navegar con sus demostraciones y ejemplos, dirigido al muy alto y muy poderoso señor Don Philipe II de este nombre Rey de España. Sevilla: Tip. Zarzuela, [1555] 1921, p.31.

${ }^{33}$ NAVARRETE, Martin Fernández de. Colección de los viages y descubrimientos que hicieron por mar los españoles desde fines del siglo XV. Vol. IV. Madrid: Imprenta Nacional, 1837, p. 161.
} 
yr a Portogal a se informar e saber secretamente del viaje de los portogueses hizieron a las Yndias con quatro navíos de donde truxeron de vuelta este año Yndios por esclavos e brasil y volvieron en este año a hazer otro viaje a la misma tierra [...] 3750 [maravedíes] ${ }^{34}$.

De modo que parece evidente que Juan de la Cosa partió a Lisboa en misión informativa en agosto de 1503. Concretamente, el 1 de agosto de ese mismo año, los reyes empezaron a recopilar información sobre los oficiales de la Casa y se decantan finalmente por Juan de la Cosa. Recordemos, no obstante, que el marino cántabro se encontraba por aquel entonces negociando las condiciones de su expedición a Urabá, de donde había sido nombrado alguacil mayor ${ }^{35}$. Sumado a esto, su participación en los dos primeros viajes colombinos y en el de Ojeda de 1499 le otorgaba una gran valía para la Corona castellana. Al hilo de esto puede resultar sorprendente que la corona decidiese arriesgar la vida de un personaje tan valioso disponiendo de otros marinos de menor calado, tal y como se hizo en 1500, cuando se envió a Diego de Lepe a averiguar sobre la misma expedición que tiene como supuesto objetivo Juan de la Cosa. La peligrosidad de la misión de 1503 queda patente en la de Lepe, que terminó con la muerte del marino en circunstancias desconocidas ${ }^{36}$.

Sin embargo, es probable que el marino santoñés fuese el más diestro en lo que a asuntos cartográficos se refiere de entre los marinos disponibles con los que contaba la corona, por lo que el espionaje cartográfico se postula como uno de los motivos encubiertos del envío de Juan de la Cosa.

El historiador portugués Armando Cortesão afirma que la producción cartográfica portuguesa de inicios del siglo XVI era anhelada por aquellas potencias que tenían intereses en el ámbito marítimo. Por ello, y fundamentalmente desde Italia y España, Lisboa recibió multitud de espías que pretendían hacerse con importantes piezas de información. Entre los citados por Cortesão encontramos a Alvise Cadamosto, Antonio de Noli, Jeronimo Münzer, Martin Behaim, Bartolomeu Colombo, Alberto Cantino, Nicolau de Caverio, Francesco Roselli, Alonso de Santa Cruz, y el mismo Juan de la Cosa; incluye por tanto Cortesão a Juan de la Cosa como uno de los espías enviados por España a hacerse con material cartográfico ${ }^{37}$.

Finalmente, para reforzar el propósito encubierto del viaje de De la Cosa, se conservan los siguientes asientos: "Dos cartas de marear que dio a la Reyna nuestra señora e para su satisfacción de los caminos que hizo a Portugal e a la corte sobre el aviso del brasil e indios que los portugueses habían traido"38"; "En ocho de diciembre se dieron a Nicoloso Despindola en nonbre de Juan de la Cosa, syete ducados que dicho Juan de la Cosa escrivió desde la corte de Segovi que se los

${ }^{34}$ PALACIO RAMOS, Rafael. Juan de la Cosa y la época de los descubrimientos: Palacio de Manzanedo, Santoña, 2 de julio-31 de agosto de 2010. Madrid: Sociedad Estatal de Conmemoraciones Culturales, 2010, p. 59.

${ }^{35}$ GARCÍA COBO, Pedro Luis [et al]. Juan de la Cosa. Op. cit., p. 111.

36 BALLESTEROS BERETTA, Antonio. La marina cántabra. I, De sus orígenes al siglo XVI Santander: Excma. Diputación Provincial de Santander, 1968, p. 126.

37 CORTESAO, Armando. Esparsos, Volume l. Coimbra: Universidade Coimbre, 1975, p. 43.

${ }^{38}$ BALLESTEROS BERETTA. La marina cántabra. Op. cit., p.125. 
havía prestado. E que se le diesen por quanto dio a la reyna nuestra señora dos cartas de marear de las Yndias que dize que valieron más de los dichos syete ducados $[\ldots]^{39, "}$.

La idea de que Juan de la Cosa dedicase su estancia en Lisboa al espionaje cartográfico parece bastante plausible. No obstante, Ballesteros-Beretta propone una alternativa a esta teoría. Apoyándose sobre los estudios de Magnaghi en los que el italiano afirma que Vespucio era un espía, lanza la hipótesis de que Juan de la Cosa fue enviado para actuar de intermediario entre la corona castellana y el espía florentino ${ }^{40}$. Quizá, Castilla tenía un especial interés en recibir las noticias relativas a la expedición portuguesa de 1501-1502, en la que Vespucio podría haber obtenido información insólita del Nuevo Mundo.

En torno a esta cuestión, es interesante la información que aporta Germán Arciniegas, afirmando que el 15 de febrero de 1502 alcanzó la escuadra lusa el que pensaban que era el límite del Tratado de Tordesillas. Se inició entonces una discusión entre Vespucio y Coelho -al parecer su relación no había sido del todo fluida desde el inicio de la expedición ${ }^{41}$ - sobre si debían o no transgredir la línea, estando a favor de ello el florentino y en contra el capitán portugués ${ }^{42}$.

La actitud de Vespucio parece extraña, pero podría explicarse si el marino supiese que tenía plena potestad otorgada por la Corona castellana para avanzar a través de la línea del tratado y recoger toda la información que pudiese sobre esa zona aunque fuese en una flota portuguesa. Salió victorioso de la disputa Américo, con lo que la escuadra avanzó más allá del límite pactado entre las coronas ibéricas. Como prueba de esto, Magnaghi esgrime el hallazgo de un bloque de mármol con las armas de Portugal -un padrão- que «solo pudo ser puesto [...] por Américo Vespucio en $1502{ }^{43}$.

Ballesteros-Beretta reflexiona también en torno a las cartas de marear traídas por Juan de la Cosa, proponiendo que estas fueran el resultado de la entrevista con Vespucio y que representasen las tierras visitadas por el florentino en su empresa lusa ${ }^{44}$. Esto entra en contradicción con el segundo de los asientos -incluido en este trabajo $\mathrm{O}^{45}$ - referido a la procedencia de las cartas, que afirma que estas fueron compradas por el precio de "syete ducados", lo que supondría que dichas cartas no estarían dibujadas por Juan de la $\operatorname{Cosa}^{46}$, sino obtenidas de algún dibujante portugués.

\footnotetext{
${ }^{39}$ PALACIO RAMOS. Juan de la Cosa y la época de los descubrimientos. Op. cit., p. 60.

${ }^{40}$ BALLESTEROS BERETTA. La marina cántabra. Op. cit., p. 127.

${ }^{41}$ LESTER, Charles Edwards y FOSTER, Andrew. The Life and Voyages of Americus Vespucius: With Illustrations Concerning the Navigator, and the Discovery of the New World. New York: Baker \& Scribner, 1846, p. 239. Se refiere Américo Vespucio a Coelho con las siguientes palabras: «Nuestro Capitán era un hombre presuntuoso y muy obstinado [...]». Traducción libre.

42 ARCINIEGAS, Germán. Why America?: 500 Years of a Name: The Life and Times of Amerigo Vespucci. Bogotá: Villegas Asociados, 2002, pp. 330-31.

${ }^{43}$ VELILLA TALAVERA, María Margarita (ed.). Aportes de Benjamin Velilla a la Historia del Paraguay. Asunción: Ediciones y Arte S.A., 2005, p. 90.

${ }^{44}$ BALLESTEROS BERETTA. La marina cántabra. Op. cit., p. 128.

${ }^{45}$ Véase nota 76 en esta misma página.

${ }^{46}$ PALACIO RAMOS. Juan de la Cosa y la época de los descubrimientos. Op. cit., pp. 59-60.
} 


\subsection{Americo Vespucio}

Intentar comprender el viaje a Lisboa de Juan de la Cosa en 1503 es imposible sin analizar la figura de Américo Vespucio. Siguiendo a Puente y Olea, Vespucio tomó parte en las dos expediciones portuguesas de 1501-1502 y 1503-1504, que, a priori, fueron las que despertaron recelos en la corona castellana ${ }^{47}$, enviando por ello a Juan de la Cosa a Lisboa.

Pero no mucho antes de esto, Vespucio se encontraba aun sirviendo a los reyes de Castilla. El porqué de la implicación del marino florentino en las citadas expediciones lusas se inicia el 15 de noviembre de 1500, fecha en la que los Reyes Católicos expidieron una carta al obispo de Córdoba por la cual otorgan al marino Diego de Lepe licencia por «tornar a descubrir con tres carabelas a la parte donde otra vez fue ${ }^{48}$. Vespucio supo de esta expedición y quiso participar en la misma. Se informó entonces a Lepe de dos expediciones que estaban preparándose en Portugal, cuyo destino sería probablemente el Brasil ${ }^{49}$. El marino ovetense, inmerso en la preparación de su nuevo periplo, fue enviado a la capital lusa con instrucciones o propósitos desconocidos, falleciendo allí en circunstancias igualmente ignotas, con lo que también es cancelado el viaje que iba a realizar con Vespucio. Esto liberó al florentino de su compromiso con la Corona castellana.

No es de extrañar que Manuel de Portugal desease reclutar para su plantilla de exploradores a un marino de la talla de Vespucio. El modo en el que lo hizo es motivo de controversia, ya que mientras que Ballesteros-Beretta afirma que, según la Carta a Soderini, Manuel de Portugal se valió de Bartolomé del Giocondo para atraerse al florentino a sus filas ${ }^{50}$, el Vizconde de Santarém remite a Fernández de Navarrete una misiva en la que comunica que:

[...] Ni en las chancillerías originales del Rey D. Manuel desde 1495 hasta 1503 inclusive, ni en los 82902 documentos del cuerpo cronológico, ni en los 6095 del cuerpo de Gavetas, ni en los numerosos paquetes de las cartas misivas de los Reyes y otros personajes aparece en documento alguno el nombre de Vespucio ${ }^{51}$.

\footnotetext{
47 PUENTE Y OLEA, Manuel de. Los trabajos geográficos de la Casa de Contratación. Sevilla: Escuela Tipográfica y Librería Salesianas, 1900, p. 21.

${ }^{48}$ BALLESTEROS BERETTA. La marina cántabra. Op. cit., p. 126. En cuanto a Diego de Lepe, la cita «[...] a la parte donde otra vez fue» se refiere a su viaje de 1500 en el que realizó un recorrido similar al que llevó a cabo Vicente Pinzón. Partiendo de Palos, se dirigió a la Isla del Fuego en Cabo Verde, alcanzó el cabo de Santo Agostinho en la costa brasileña -según D'Avezac-, y finalmente puso rumbo al norte hasta la desembocadura del Amazonas, finalizando su periplo en las posesiones españolas del Caribe. En: RIBEIRO, Darcy; ARAÚJO MOREIRA, Carlos de y ARAÚJO MOREIRA, Gisele Jacon de. La fundación de Brasil: testimonios 1500-1700. Venezuela: Fundacion Biblioteca Ayacucho, 1992, p. 23.

${ }^{49}$ Estas expediciones probablemente se refieran a las mismas en las que después participó Américo Vespucio; tanto la fecha como el interés de los monarcas castellanos por hacerse con la información sobre las mismas -enviando primero a Diego de Lepe y embarcando después a Vespucio- apuntan a ello.

${ }^{50}$ BALLESTEROS BERETTA. La marina cántabra. Op. cit., p.126.

${ }^{51}$ La participación de Vespucio en el viaje portugués de 1501-1502 es respaldada en la historiografía del siglo XX por múltiples especialistas que otorgan una autenticidad total a las cartas escritas por el florentino -desde Cabo Verde en junio de 1501 y otra desde Lisboa en Julio de 1502- dirigidas a Lorenzo de Pier Francesco dei Medici en las que relataba los acontecimientos de dicha expedición,
} 
Tampoco se encuentran en los mismos cuerpos indicaciones algunas de Julian del Giocondo, y de Bartolomé del Giocondo ${ }^{52}$.

En cualquier caso, el marino florentino se unió a la escuadra portuguesa que partió de Lisboa el 13 de mayo de 1501. Al frente de la misma se encontraba Gonzalo de Coelho ${ }^{53}$. El devenir de esta expedición ha generado notables divergencias entre los estudiosos de la cuestión, ya que según la Carta a Soderini este viaje costeó la América Meridional hasta el grado 50, habiendo descubierto por tanto el Río de la Plata y quedándose relativamente cerca del Estrecho de Magallanes ${ }^{54}$. La escuadra de Coelho regresó a Lisboa en junio de $1502^{55}$.

No exento de polémica está el segundo viaje bajo bandera portuguesa de Vespucio, también con Gonzalo de Coelho al mando, comprendido entre 1503 y 1504. La participación del florentino ha sido seriamente puesta en duda debido a que el único documento que refleja los acontecimientos sucedidos en la misma es la Carta a Soderini o Lettera ${ }^{56}$, autógrafa del propio Vespucio. Esta expedición, que partió el 10 de mayo, tuvo como objetivo encontrar la isla de Malaca. Navegaron hasta el archipiélago de Cabo Verde y tras algunas disensiones entre Vespucio y Coelho, continuaron navegando hacia el Nuevo Mundo -previo paso por el archipiélago Fernando de Noronha-, donde tomaron tierra en la Bahía de todos los Santos. La escuadra regresó a Lisboa el 18 de junio de $1504^{57}$.

Más allá del recorrido realizado por la flota lusa en este viaje, es interesante la autenticidad o falsedad del documento que la refiere ${ }^{58}$, ya que podría servir para

además de una anterior fechada en julio de 1500, desde Sevilla, en la que relataba su primer viaje. En: VERLINDEN, Charles y PÉREZ-EMBID, Florentino. Cristóbal Colón y el descubrimiento de América. Madrid: Ediciones Rialp, 2006, p. 158.

52 NAVARRETE, Martín Fernández de. Colección de los viages y descubrimientos que hicieron por mar los Españoles, desde fines del siglo XV, con varios documentos inéditos concernientes a la historia de la marina castellana y de los establecimientos españoles en India. Madrid: Imprenta nacional, 1829, p. 310. También en FONTOURA COSTA, Abel. Cartas das Ilhas de Cabo Verde de Valentim Fernandes, 1506-1508. Aveiro: Divisao de Publicacoes e Biblioteca da Agencia Geral das Colonias, 1939, p. 94., se cita que no existe un solo documento en los Archivos Nacionales de su presencia en Portugal.

53 LAGUARDA TRÍAS, Rolando A. El predescubrimiento del Río de la Plata por la expedición portuguesa de 1511-1512. Lisboa: Junta de Investigaçoes do Ultramar, 1978, p. 59.; PALACIO RAMOS. Juan de la Cosa y la época de los descubrimientos. Op. cit., p. 59.

${ }^{54}$ BALLESTEROS BERETTA. La marina cántabra. Op. cit., pp. 126-27.

55 PRESTAGE, Edgar. Descobridores portugueses. Lisboa: Edições da 1a Exposição Colonial, 1934, p. 339 .

56 «La Lettera di Américo Vespucio delle isole nuovamente ritrovate in Quattro suoi viaggi, publicada sin lugar ni fecha, pero en Florencia (1505-1506), y dirigida al gonfaloniero Pietro Soderini. Es la comúnmente llamada Lettera a Soderini». En: VERLINDEN, Charles y PÉREZ-EMBID, Florentino. Cristóbal Colón y el descubrimiento de América. Op. cit., p. 159.

${ }^{57}$ LESTER, Charles Edwards y FOSTER, Andrew. The Life and Voyages of Americus Vespucius. Op. cit., pp.239-42.

${ }^{58}$ En torno a la veracidad de los escritos autografiados por Vespucio han corrido ríos de tinta durante todo el siglo XX y, en menor medida, en lo que llevamos de siglo XXI. Entre los detractores de su autenticidad podemos citar a Alberto Magnagui, que no reconoce como veraces las cartas conocidas como Mundus Novus (1504) y Lettera a Soderini pero si acepta las remitidas a Lorenzo Pier de Medici (véase MAGNAGHI, Alberto. Amerigo Vespucci: studio critico, con speciale riguardo ad una nuova valutazione delle fonti e con documenti inediti tratti dal Codice Vaglienti (Riccardiano 1910). 2 voll. 
desechar uno de los posibles objetivos del viaje a Lisboa de Juan de la Cosa; de ser cierta la participación de Vespucio en este viaje, el encuentro entre ambos en la capital lusa no habría tenido ocasión de producirse. El escrito contiene cuatro viajes: el primero, realizado en 1497 al servicio de los Reyes Católicos; el segundo, realizado en 1499, se identificaría con la expedición realizada junto a Alonso de Ojeda y Juan de la Cosa; el tercero, realizado en 1501, se identificaría con el primero de sus viajes portugueses; y el cuarto, realizado en 1503, se identificaría con el segundo de los viajes bajo bandera lusa.

Finalmente, en lo que a Américo Vespucio concierne, cabe destacar la posibilidad de que fuese un espía al servicio de la corona castellana en todo momento, incluso cuando realizó el viaje (o los viajes) al continente americano bajo bandera portuguesa. Esta hipótesis sería la que mejor explicaría las misteriosas andanzas del marino florentino en Portugal y su retorno a Castilla sin ningún tipo de reprimenda o castigo por parte de los Reyes Católicos. De hecho, a su regreso, la archiduquesa Juana proclamaba lo siguiente el día que le fue concedida la naturaleza castellana: "Por facer bien y merced a vos Amerigo Vespuche, florentín, acatando vuestra fidelidad e algunos buenos servicios que me habéis fecho e espero que me haréis de quí en adelante" 59 .

El historiador británico Edgard Prestage comulga con la idea de Magnaghi, reflejándolo categóricamente con la siguiente afirmación: "Era, de hecho, un espía; y sus observaciones sobre los capitanes y pilotos portugueses sugiere que este prestaba poca atención a los conocimientos náuticos con los que pretendía hacerse" 60 .

\subsection{Angelo Trevisan}

No son muchas ni muy precisas las informaciones de las que disponemos sobre Angelo Trevisan, secretario del embajador veneciano en Castilla en $1501^{61}$. No obstante, de gran relevancia resultan las cartas que escribió a su amigo Domenico Malipiero en agosto del citado año, las cuales incluimos a continuación:

Esperamos cada día a nuestro doctor de Lisboa, que dejó a nuestro magnifico embajador allí; el cual a instancias mías ha escrito un breve relato del viaje [portugués] desde Calicut, del que haré una copia para Vuestra Magnificiencia. Es imposible conseguir el mapa de ese viaje porque el rey ha decretado pena de

Roma: A.G.A.R, 1924); BETANZOS, Miguel. Americo Vespucio. Buenos Aires: Penguin Random House Grupo Editorial Argentina, 2012). Frederick Julius Pohl, por su parte, cuestiona también la Lettera a Soderini (véase POHL, Frederick Julius. Amerigo Vespucci: Pilot Major. London: Routledge, 1966) y en el marco de una investigación más actual es Felipe Fernández-Armesto quien discute la honradez de la pluma de Américo en esto textos, siguiendo la estela dejada por Magnaghi y Pohl (véase FERNÁNDEZ-ARMESTO, Felipe. Amerigo. The man who gave his name to América. London: Weidenfeld \& Nicholson, 2006). El principal defensor de la legitimidad de las cartas del florentino es Roberto Levillier (véase: LEVILLIER. América la Bien Llamada. Op. cit.)

${ }^{59}$ BALLESTEROS BERETTA. La marina cántabra. Op. cit., p. 128. «Por esta frase, Vespucio fue acusado de espía en Portugal y de agente secreto de Castilla» En: QUINTANA, Litza. 500 años después. Tegucigalpa: Universidad Nacional Autónoma de Honduras, 1992, p. 222.

${ }^{60}$ PRESTAGE. Descobridores portugueses. Op. cit., p. 339.

${ }^{61}$ BROTTON, Jerry. Historia del mundo en 12 mapas. Barcelona: Debate, 2014, pp. 277-278. 
muerte para cualquiera que lo divulgue ${ }^{62}$.

$\mathrm{Ni}$ siquiera un mes separa estas palabras del documento que se cita a continuación:

Si regresamos vivos a Venecia, Vuestra Magnificiencia verá mapas que llegan no solo a Calicut sino más allá a menos del doble de la distancia de aquí a Flandes. Os prometo que todo ha llegado en buen estado; pero eso puede que Vuestra Magnificiencia prefiera no divulgarlo. Una cosa es segura: que a nuestra llegada os enterareis de tantos detalles como si hubierais estado en Calicut y más allá63.

Parece evidente que en el breve lapso de tiempo que separa ambos documentos Angelo Trevisan consiguió obtener documentos cartográficos de gran relevancia, esquivando las penas de muerte que el monarca portugués acababa de implantar, convirtiéndose así en uno de los agentes que logró imponerse a la política del sigilo y extraer de Lisboa información cartográfica a priori secreta ${ }^{64}$.

Si comparamos la correspondencia intercambiada por Trevisan y Cantino con sus señores vemos una acusada diferencia. Trevisan hace saber en una primera misiva que no va a ser capaz de extraer ningún mapa de Lisboa, teniendo que recular cuando poco después es capaz de burlar la seguridad lusa y extraer documentación clasificada. Por su parte, Cantino no duda en ningún momento de que va a conseguir el Planisferio, haciendo mención al mismo solo en la misiva enviada desde Roma el 19 de noviembre de $1502^{65}$. Mientras Trevisan se ve obligado a comunicar las dificultades que tiene que afrontar para sustraer material cartográfico, Cantino no dedica atención a este aspecto en sus cartas, pues es una cuestión que ya había sido solventada; consecuentemente, informaciones como las andanzas del embajador veneciano Pasqualigo o los acontecimientos que se están sucediendo en Lisboa a inicios de siglo son un material de lo más interesante para compartir con su señor.

\section{Alberto Cantino, ¿una fuga?}

La misión llevada a cabo por Alberto Cantino en Lisboa presenta escasas similitudes con las efectuadas por La Cosa, Vespucio o Trevisan, tanto en el marco circunstancial en el que se desarrollaron como en los sucesos que acontecieron durante las estancias de los protagonistas.

El papel de Cantino en la capital lusa ha ido evolucionando a la par que la historiografía en torno al Planisferio Anónimo de 1502. En la obra clásica Portugaliae

\footnotetext{
62 Ibídem. Citado de GREENLEE, William B. The Voyage of Pedro Alvares Cabral to Brazil an India. Londres, 1937, pp.123-124.

${ }^{63}$ Ibídem, p. 17. Citado de GREENLEE, William B. The Voyage of Pedro Alvares Cabral to Brazil an India. Op. cit., pp.123-124.

${ }^{64} \mathrm{~N}$. del. A.: El estudio de la figura de Angelo Trevisan se encuentra aún en estado embrionario, por lo que nos limitaremos a estas informaciones, no queriendo incurrir en errores historiográficos derivados de la precipitación y las pocas fuentes que hemos encontrado por el momento.

${ }_{65}$ SÁNCHEZ MARTíNEZ, Antonio. La espada, la cruz y el Padrón: soberanía, fe y representación cartográfica en el mundo ibérico bajo la Monarquía Hispánica, 1503-1598. Madrid: Consejo Superior de Investigaciones Científicas, 2013, p. 81.
} 
Monumenta Cartographica se recoge lo siguiente sobre la cuestión:

Alberto Cantino fue un agente secreto de Ercole d'Este, Duque de Ferrara, quien le envió a Lisboa para obtener información sobre los descubrimientos portugueses. Cantino, que ya había estado en Lisboa, aparentemente disfrazado de vendedor de caballos, sobornó a un cartógrafo portugués desconocido para que le hiciera un mapamundi, quizás copiado (al menos en parte) del Padrón Real, o de un mapa estándar que hubiera registrado los descubrimientos tan pronto como habían llegado a Lisboa ${ }^{66}$.

El texto parece hablarnos de un hombre de pocos recursos más allá del oro italiano, aunque suficiente para sobornar a un cartógrafo sedicioso que preparase la codiciada carta siguiendo lo estipulado en el padrón real portugués.

En la Revista de Indias, editada por el CSIC, encontramos lo siguiente: "EI propio Alberto Cantino era un espía enviado a Lisboa por Ercole d'Este, duque de Ferrara, para reunir todas las informaciones posibles sobre los descubrimientos portugueses. Logró engañar a un cartógrafo portugués...67".

La idea de Cortesão de un Alberto Cantino enviado a Lisboa sin ningún tipo de red de seguridad más allá del montante de dinero que lo acompañaba se apuntaló en la historiografía del siglo XX y llegó hasta nuestros días, estando presente aún en algunas publicaciones no especializadas en la materia. Los estudios más recientes sobre el Planisferio y su entorno escapan a esa concepción, como puede apreciarse en el siguiente extracto de $\mathrm{O}$ Planisferio de Cantino e o Brasil de Lourenço Fernandes: "[...] Era sin duda un agente muy bien situado y con contactos en el ambiente naval de Lisboa, así como en la corte portuguesa. Se logró infiltrar de tal manera que tuvo acceso a la misma sala del trono ${ }^{68,}$.

Lo que sí parece un hecho irrefutable en cualquier documento que haga referencia a Alberto Cantino es que era un espía. No parece presentar duda alguna que consiguiera su cometido de forma ilícita, sobornando, engañando e intrigando en la dinámica corte lusa de inicios del siglo XVI. Desde este estudio se plantea la posibilidad de que esta aserción pudiera no ser cierta, teniendo en cuenta una serie de factores en torno a la llegada de Cantino y a la elaboración del Planisferio que, tradicionalmente, no se han tenido en cuenta.

El primero de ellos es la relación establecida entre Portugal y Ferrara, que ya se ha expuesto con detenimiento en este mismo estudio. El segundo son las diferencias de preparación, desarrollo y resultados con las fugas de inicios del siglo XVI de las que se tienen datos suficientes para ser estudiadas y comparadas, proceso llevado a cabo previamente en este trabajo. El tercero son los resultados de un estudio

\footnotetext{
${ }^{66}$ CORTEÇAO, Armando y TEIXEIRA DA MOTA, Avelino. Portugaliae monumenta cartographica. Lisboa: Imprenta Nacional-Casa da Moeda, 1987, p. 7.

${ }^{67}$ FALL, Yoro K. Las cartas de rumbos y su utilización en los siglos XIV y XV (1). Revista de Indias. 1983, n. XLIII, p. 435.

${ }^{68}$ LOURENÇO FERNANDES, Fernando. O Planisferio de Cantino e o Brasil. Lisboa: Academia de Marinha, 2003, p. 51. Para esta cuestión es también interesante consultar MILANO, Ernesto. Carta del Cantino: All' Edizione in Facsímile. Módena: II Bulino, 2004.
} 
específico en torno al valor del Planisferio y al análisis comparativo del mismo con otros documentos cartográficos de la época, cuestión que es abordada por el autor en otro trabajo. El cuarto factor es el análisis de la presencia en Lisboa de Cantino a través del intercambio de misivas que se produjo con Ercole d'Este. En este apartado serán examinadas tres ${ }^{69}$ enviadas en enero, julio y octubre de 1501.

Eclipsado por el éxito de su misión y por la relevancia para la historia de la cartografía del Planisferio Anónimo de 1502, Alberto Cantino y su papel de embajador en Lisboa en 1501 y 1502 han pasado a un segundo plano. Consecuentemente, el estudio de las cartas enviadas a Ferrara se ha centrado en la última de las mismas, la que contiene información concreta sobre la expedición del citado planisferio. El análisis de las otras cartas, que atienden a asuntos exclusivamente diplomáticos y de traslado de informaciones, supone una fuente de información riquísima sobre los acontecimientos que más interés despertaban en una ciudad como Lisboa a inicios del siglo XVI. Se procede a continuación al estudio exhaustivo de cada uno de los aspectos que Cantino considera oportuno comunicar a su patrón en las citadas cartas, cuya transcripción puede ser consultada en el apéndice documental.

La primera de las misivas (Apéndice 1) relata con todo lujo de detalles el nombramiento de Vasco de Gama como Almirante de las Indias, lo que nos permite acercarnos al desarrollo de este tipo de ceremonias en la Lisboa de aquella época. Pero en el inocente relato de Cantino se esconden algunas informaciones que merecen una atención especial. En el inicio menciona la existencia de "otra carta de este mes", lo que nos indica que no disponemos de todas las misivas enviadas al duque desde la capital lusa y que la correspondencia era relativamente continua.

Antes de comenzar a describir la ceremonia, Cantino apunta que Vasco da Gama deberá partir en diez días (9 de febrero de 1501) para bloquear la entrada del Mar Rojo al comercio otomano. Estas fechas provocan cierta confusión ${ }^{70}$ si leemos lo que João de Barros escribió en su Primeira Década:

Antes de partir esta frota, [Nota 1: A frota de vinte velas que D. Manuel mandou à Indía em 1502 e cujo comando deu a D. vasco da Gama] estando El-rei em Lisboa, a 30 de Janeiro foi ouvir missa a Sé; e, depois de acabada, com solene fala, relatando os méritos de D. Vasco da Gama, o fez Almirante dos mares de Arábia, Pérsia, Índia, e de todo o Oriente. No fim do qual acto El-rei lhe entregou a bandeira do cargo que levava, e daí foi levado por tôdolos principais Senhores e Fidalgos que eran presentes, com grande pompa, até os casi da Ribeira, onde

\footnotetext{
${ }^{69}$ N. del A.: Se ha podido acceder a una cuarta fechada a 17 de octubre de 1501 (En: PERAGALLO, Prospero [et al.]. Carta de el-rei D. Manuel ao rei catholico narrando-lhe as viagens portuguezas à India desde 1500 até 1505; reimpressa sobre o prototypo romano de 1505, vertida em linguagem e anotada por Prospero Peragallo: seguem em appendice a relação analoga de Lunario Cha Masser e dois documentos de Cantino e Pasqualigo. Lisboa: Typographia da Academia Real das Sciencias, 1892, pp. 100-102, que relata la odisea sufrida por los barcos que retornaron de la expedición de Gaspar Corte-Real. Dado que estas informaciones no hacen referencia a la estancia de Cantino en Lisboa no hemos encontrado espacio para ella en este artículo.

${ }^{70}$ Sobre esta cuestión reflexiona e investiga el propio Henry Harrise en CANTINO, Alberto; HARRISE, Henry y ALMEIDA, Frederico de (eds). Document inédit concernant Vasco da Gama. Op. cit.
} 
embarcou $^{71}$.

Del mismo modo lo refleja Gaspar Correia en sus Lendas da Índia: "E no anno seguinte, de 1502, veo à India outra vez dom Vasco da Gama, com dezanove velas grossas e caravellas latinas ${ }^{72, "}$.

Y también Fernão Lopes de Castanheda en su Historia do Descobrimento e Conquista da India pelos portugueses: "[...] Deu a Dom Vasco da Gama [la capitanía de la armada] que com ho regimento do que avia de fazer se partio de Lisboa a dez de Fevereyro, de mil \& quinhentos \& dous levando em sua conserva dez naos grossas... "33".

La coincidencia de tres de las más destacadas fuentes de la época incita a pensar que el futuro viaje comandado por Vasco da Gama que Cantino describe habría tenido lugar en febrero de 1502, y no de 1501, año en el que está fechada la carta.

También interesantes resultan las palabras que siguen: "[...] El rey Manuel no quiere lidiar con ninguna otra soberanía ni navíos en esos mares, aunque le dijo al embajador veneciano que, si ese año sus negocios no eran prósperos, como se cree, abandonaría la empresa, ya que el año pasado sus pérdidas ascendieron a 80,000 ducados". Tal y como se ha analizado en la sección dedicada a las relaciones con Venecia, esto distaba mucho de ser cierto, por lo que es obvio que el monarca intentaba confundir al embajador veneciano, que, a finales de 1501, escribía a la Serenissima informando del constante envío de navíos armados por parte del monarca hacia Calicut ${ }^{74}$.

A continuación, Cantino, cambia totalmente de registro y le relata al duque con toda la precisión que puede la ceremonia oficiada en la Sé de Lisboa. De este fragmento resulta interesante para este estudio la nueva alusión que se hace al embajador de Venecia, quien siempre parece tener un papel destacable en la correspondencia con Ferrara, como veremos más adelante.

Finalizada la descripción de lo acontecido en la catedral lisboeta se produce un nuevo cambio de registro en el que Cantino comunica a su patrón una serie de sucesos relacionados con España. Relata la caída en desgracia de un duque de Sibila, Sibilla o Sibillia, que se ha reconocido como Sevilla por la similitud gráfica y por la identificación de tal duque como Juan Alonso Pérez de Guzmán y Ribera, VIII señor de Sanlúcar de Barrameda, V conde Niebla, III duque de Medina Sidonia, II marqués de Gibraltar y I marqués de Cazaza en África. De su primer matrimonio con Isabel Fernández de Velasco nació Leonor de Mendoza, que se desposó con Jaime I

${ }^{71}$ BARROS, João de. Primeira decada da Asia [en línea]. Lisboa: Aillaud, [1552] 1920, p. 151. Disponible en <http://archive.org/details/primeiradecadada00barr>.

72 CORREIA, Gaspar. Lendas da India, ed. Rodrigo José De Lima Felner. Lisboa: Typ. da Academia Real das Sciencias, 1864 , p. 3.

73 LOPES DE CASTANHEDA, Fernão. Historia do descobrimento e conqvista da India pelos Portvgveses. Lisboa: Typographia Rollandiana, 1833, p. 130.

${ }^{74}$ También Giovanni Francesco de la Faitada escribía a la Serenissima en octubre de 1503 sobre los movimientos en Portugal en las Indias Orientales. Véase nota al pie 14. 
de Braganza, IV duque de Braganza, el duque citado en el texto de Cantino, y, por tanto, yerno de Juan Alonso Pérez ${ }^{75}$. En diversas publicaciones consultadas a efectos de este texto ${ }^{76}$, se establece la fecha de este matrimonio en 1502, lo cual parece imposible si tenemos en cuenta que Cantino se refiere a Jaime I de Braganza como "yerno" de Juan Alonso Pérez, por lo que el matrimonio debería haberse producido, como pronto, a inicios de 1501, o, probablemente en el año de 1500. Indica Cantino que Jaime I de Braganza, pide al rey que se envíen embajadores a España para devolverle sus tierras a Juan Alonso Pérez.

Informa Cantino a continuación de que el archiduque de Borgoña, es decir, Felipe el Hermoso, se encuentra en ese momento en Burgos, dando detalles incluso del séquito que acompaña a su esposa y de donde se encontrará el rey de España con él. Lo curioso de esta información es que no podría haber acontecido así, ya que Felipe el Hermoso no entró en España hasta el 26 de enero de 1502, a través de Fuenterrabía (País Vasco) y siendo recibido por Gutiérrez de Cárdenas -Gran Comendados de León- y Francisco de Zuñiga -conde de Miranda ${ }^{77}$. Su presencia en Burgos, que según Cantino tuvo lugar a finales de enero de 1501, no se hizo efectiva hasta el 12 de febrero de 1502, donde fue recibido por D. Bernardino de Velasco, Condestable de Castilla, D. Francisco de la Cueva, duque de Albuquerque y el conde de Siruela ${ }^{78}$.

De tres de los acontecimientos relatados por Cantino, dos ocurrieron con total seguridad en 1502, y el tercero -el segundo viaje de Vasco de Gama a la India- casi incontestablemente también. Esta eventualidad parece apuntar a una obviedad: la carta está mal fechada. Pero, aún en el caso de que fuera escrita en 1502, ¿cómo explicar que Cantino hablase de la presencia de Felipe el Hermoso en Burgos trece días antes de que se produjese su llegada? Por el momento no parece posible dar respuesta a esta pregunta.

El segundo documento (Apéndice 2), un fragmento de una carta enviada el 19 de julio de 1501, también presenta sus incógnitas. La primera parte del texto alude sin duda a Catalina de Aragón, quien debía navegar a territorio británico para sus nupcias con el príncipe de Gales. Los estudios actuales sobre esta cuestión, así como las crónicas y compilaciones de siglos anteriores, aceptan agosto como el mes de partida de la expedición desde La Coruña ${ }^{79}$. Y, no obstante, dicha partida está siendo narrada por Cantino, supuestamente, el día 19 de julio. Al menos en este

\footnotetext{
${ }^{75}$ Dos años después del matrimonio, Jaime I de Braganza asesinó a su esposa. Este hecho inspiró la célebre comedia de Lope de Vega "El más galán portugués". En: SOLER SALCEDO, Juan Miguel. Nobleza española: grandeza inmemorial, 1520. Madrid: Editorial Visión Libros, 2008, p. 300.

${ }^{76}$ Por citar algunos: VARIOS, Sociedad V Centenario del Tratado de Tordesillas, y Comissão Nacional para as Comemorações dos Descobrimentos Portugueses (eds.). La Paz y la Guerra en la época del Tratado de Tordesillas. Madrid: Electa España, 1994, p. 99; COMMIRE, Anne y KLEZMER, Deborah. Women in World History: Gab-Harp. Open Library: Yorkin Publications, 1999, p. 655. En: CORDEIRO, Luciano. A senhora duqueza. Lisboa: Livraria Ferin, 1889, p. 347.

${ }^{77}$ CERRO BEX, Victoriano del. Itinerario seguido por Felipe I el Hermoso en sus dos viajes a España. Chronica Nova. 1973, n. VIII, p. 65.

${ }^{78}$ Ibídem, p. 66.

${ }^{79}$ Entre otras muchas publicaciones: LADERO QUESADA, Manuel Fernando. Recibir princesas y enterrar reinas (Zamora 1501 y 1504). Espacio Tiempo y Forma [en línea]. 2000, n. 13, p. 121. Disponible en <http://revistas.uned.es/index.php/ETFIII/article/view/3656>.
} 
caso el año parece coincidir con los acontecimientos referidos. La segunda parte del texto resulta también de gran interés. Lo que Cantino parece estar narrando aquí es un auto de fe inquisitorial en la ciudad de Sevilla, en el cincuenta y cuatro hombres son quemados por herejes y por adorar a una joven que recibe castigo idéntico ${ }^{80}$.

El tercer y último documento (Apéndice 3) incorpora la noticia de la llegada de una carabela española a Calice, un relato sobre la llegada de Catalina de Aragón a Inglaterra, una descripción del palacio de Sintra a inicios del siglo XVI e informaciones sobre lo que está aconteciendo en los territorios africanos de Don Manuel.

En cuanto a la llegada de la carabela a Calice, es necesario primero identificar tal puerto. En el Suplimento All'Historia della Vita del Catholico Re delle Espagne..., obra editada en Venecia y escrita en italiano, se narra la toma de Cádiz por los ingleses en el marco de la guerra anglo-española. A lo largo del relato, la ciudad asediada por el ejército británico aparece siempre denominada como Calice ${ }^{81}$, por lo que parece evidente que Cantino se refería al puerto de Cádiz. Pero, ¿qué expedición española entró en el puerto de Cádiz el día 5 de octubre de 1501?

\footnotetext{
${ }^{80} \mathrm{~N}$. del A.: La documentación sobre penas inquisitoriales en el siglo XVI, custodiada en el Archivo Histórico Nacional, está aún pendiente de revisión. El hallazgo de otro documento que fechase este acontecimiento podría resultar de gran interés.

${ }^{81}$ CAMPANA, Cesare y CAMPANA, Agostino. Supplimento All'Historia Della Vita Del Catolico Re delle Spagne, D. Filippo II. d' Austria; Cioè Compendio di quanto nel mondo è avvenuto dall'anno 1583 fino al 1596 D’Agostino Campana Et Historia Universale di quant' è occorso dal 1596 fino al 1599 Di Cesare Campana Aquilano, vol. V. Venecia: Apresso Bartolomeo Carampello, 1609, pp. 98100.
} 
Entre 1499 y 1501 fueron enviadas mútiples empresas desde Castilla ${ }^{82}$ :

\begin{tabular}{|c|c|c|c|}
\hline \multicolumn{4}{|c|}{ Empresas enviadas desde Castilla entre 1499-1501 } \\
\hline Explorador/es & Fecha de partida & Fecha de retorno & $\begin{array}{l}\text { Puerto de } \\
\text { llegada }\end{array}$ \\
\hline $\begin{array}{l}\text { Alonso de Ojeda, Juan de } \\
\text { la Cosa, Américo } \\
\text { Vespucio }\end{array}$ & 18 de mayo de 1499 & $\begin{array}{l}\text { Finales de junio } \\
\text { de } 1500\end{array}$ & Cádiz \\
\hline $\begin{array}{l}\text { Pedro Alonso } \\
\text { Cristóbal Guerra }\end{array}$ & $\begin{array}{l}\text { Finales de mayo de } \\
1499 \text {-primeros de junio } \\
\text { de } 1499\end{array}$ & $\begin{array}{l}\text { Mediados de abril } \\
\text { de } 1500\end{array}$ & $\begin{array}{l}\text { Bayona la Real } \\
\text { (Pontevedra) }\end{array}$ \\
\hline Vicente Yañez Pinzón & $\begin{array}{l}\text { Finales de noviembre- } \\
\text { principios de diciembre } \\
\text { de } 1499\end{array}$ & $\begin{array}{l}\text { Finales (30) de } \\
\text { septiembre de } \\
1500\end{array}$ & $\begin{array}{l}\text { Palos de la } \\
\text { Frontera (Huelva) }\end{array}$ \\
\hline Diego de Lepe & Diciembre de 1499 & Octubre de 1500 & ¿? \\
\hline $\begin{array}{l}\text { Rodrigo de Bastidas, } \\
\text { Juan de la Cosa }\end{array}$ & Octubre de 1500 & $\begin{array}{l}\text { Septiembre de } \\
1502\end{array}$ & Cádiz \\
\hline Vélez de Mendoza & Agosto de 1500 & $\begin{array}{l}\text { Finales de junio } \\
\text { de } 1501\end{array}$ & Sevilla \\
\hline Cristóbal Guerra & $\begin{array}{l}\text { ¿25 de agosto de } \\
1500 ?\end{array}$ & $\begin{array}{l}\text { ¿5 de octubre de } \\
1501 ?\end{array}$ & Cádiz \\
\hline
\end{tabular}

Fig. 1: Empresas enviadas desde Castilla entre 1499-1501. Fuente: Elaboración propia.

Si analizamos la tabla, la única de las expediciones que podría coincidir con la referida por Cantino es la última, la de Cristóbal Guerra. Así lo expresa también Alicia Bache Gould en la Nueva lista documentada de los tripulantes de Colón:

[Refiriéndose a la expedición] Una de las dos carabelas se perdió: la otra regresó a Cadiz. El sueldo del maestre de esta, Francisco Gálvez, corre desde el 25 de agosto del 1500 hasta el 15 de octubre de 1501, pero el maestre ha debido seguir en el servicio unos días después de la llegada, porque existe una carta de Alberto Cantino que dice que regresó el 5. [...] No puede ser sino la carabela sobreviviente del viaje de Guerra ${ }^{83}$.

La precisa información sobre este suceso nos permite garantizar que la carta está bien fechada. Aborda a continuación la cuestión de la llegada a Inglaterra de Catalina de Aragón, narrando los hechos con gran precisión. También interesantes resultan las últimas palabras de Cantino sobre esta cuestión: "Así que uno, que en

\footnotetext{
82 Obviamente, en la elaboración de esta fuente se han omitido expediciones sobre las que no hay informaciones suficientes para ser incluidas. Para la elaboración de la tabla han sido empleadas las siguientes fuentes: VEGA I PAGÁN, Ernesto. El Almirante: la extraordinaria saga de Cristóbal Colón. Caracas: Presidencia de la República de Venezuela, 1993, p. 29; IRVING, Washington. Viajes y descubrimientos de los compañeros de Colon. Madrid: Gaspar y Roig, 1854, p. 11; NAVARRETE, Martín Fernández de. Colección de los viages y descubrimientos que hicieron por mar los españoles desde fines del siglo 15 ... coordinada é ilustrada por Martin Fernández de Navarrete. Vol. IV, p. 555.; Real Academia de la Historia (Spain) (ed.). Congreso de Historia del Descubrimiento (1492-1556): actas (ponencias y communicaciones). Madrid: Real Academia de la Historia, 1992, p. 659.; VERLINDEN, Charles y PÉREZ-EMBID, Florentino. Cristóbal Colón y el descubrimiento de América. Madrid: Ediciones Rialp, 2006, p. 143; GOULD, Alice B. Nueva lista documentada de los tripulantes de Colón en 1492. Madrid: Real Academia de la Historia, 1984, p. 342.

${ }^{83}$ GOULD, Alice B. Nueva lista documentada... Op. cit., p. 342.
} 
poquísimos días ha llevado al Rey y ala Reina esta noticia, ha recibido como recompensa de la reina cien ducados de oro". Todo parece apuntar a que Cantino se refiere a un tercero, que ha llevado a la reina la información que relata en su carta, teniendo él la posibilidad de estar presente en dicho momento dada su posición privilegiada en la corte de Lisboa. Otra posibilidad, que parece más remota a tenor de la omisión del sujeto yo en el relato, es la de que Cantino se esté refiriendo a sí mismo en tercera persona. Esta teoría se apoyaría principalmente en el hecho de que Cantino ya estaba siguiendo la suerte de Catalina de Aragón anteriormente, como aparece reflejado en su carta de 19 de julio de 1501. De ser así, podría confirmarse que estaba sirviendo a otro poder, en calidad de mensajero o espía, pero llevándoles información por la cual recibiría un pago. Además, lo haría y se lo comunicaría a su patrón, por lo que, en el caso de que Cantino estuviera haciendo referencia a su persona, el duque de Ferrara estaría al corriente de sus actividades y habría dado su aprobación. No obstante, como se introducía al principio de la reflexión sobre este fragmento del texto, parece más plausible que Cantino se estuviese refiriendo a las acciones de un informante externo y no a las suyas propias.

Incidiendo en su posición de privilegio en Lisboa, Cantino continúa relatando como ha sido invitado por el monarca para visitar su palacio de Sintra, en compañía, por supuesto, del embajador de Venecia, al que nunca olvida citar el enviado de Ercole D’Este. La descripción del palacio es sublime, no omitiendo ningún detalle, y con tiempo aún para adular al duque y realzar la belleza del palacio de Belguardo. Destacable resulta también como incide Cantino en la buena imagen del duque que está dando a Don Manuel.

Finalmente, tenemos la alusión a un levantamiento de moros en las tierras africanas de Don Manuel en el mes de septiembre de 1501, lo cual, según indica Cantino, afectó bastante al monarca. Cuenta también que la toma de trescientos fue motivo de alborozo en la capital lusa, así como un nuevo decreto introducido por el monarca que parece una especie de servicio militar obligatorio en las colonias para aquellos que delincan en Portugal, aunque si regresan, habiendo cumplido su misión, serán generosamente recompensados. Cantino expresa su opinión sobre un posible retorno, al cual no da crédito alguno, si bien menciona un lugar llamado Santa Cruz al que imbuye de cualidades paradisiacas que provocaron incluso la huida de cinco marineros.

Tal lugar podría ser Santa Cruz de Cabo de Aguer, la única toponimia para Santa Cruz que podemos ubicar en África. Esta es la descripción de la plaza que podemos encontrar en un tratado del siglo XVIII: "Pueblo de África en la Costa de Berbería, en la Provincia de Suze, en el reyno de Marruecos, casi frente a las Canarias, con un Puerto, y un Fuerte. La quitaron los moros a los portugueses en 1536. Está en un extremo de el Atlas, sobre el Cabo de Aguer. Longitud 7 grados 40 minutos, latitud 30 grados 30 minutos $^{84 "}$.

\footnotetext{
${ }^{84}$ DE LA SERNA, Juan. Diccionario geográfico, ò descripción de todos los Reynos... Madrid: Joachin Ibarra, 1763, p. 131. La fortaleza solo fue fundada en 1505 por Lopes de Sequeira. En: DE TORRES, Diego. Relación del origen y suceso de los Xarifes y del estado de los reinos de Marruecos, Fez y Tarudante. Madrid: Siglo Veintiuno, 1980, pp. 82-83.
} 
En cuanto a la revuelta de capitaneada por treinta gentilhombres en las fronteras de las colonias lusas, podemos aventurar que se trata de algún episodio enmarcado en la política de expansión africana programada por D. Manuel I85, la cual, rechazada por los Reyes Católicos, no habría tenido gran impacto. No obstante, según Cantino parece que el rey luso, ya en 1501, tenía establecidas unidades militares en el continente y planeaba aumentar el número de las mismas a través del decreto referido en la misiva.

Como puede observarse en las dos cartas que nos han llegado completas, Cantino mantiene un mismo esquema: información actualizada y relevante, relato descriptivo y casi didáctico, y noticias nuevamente de actualidad y significativas. Por otro lado, las informaciones que contienen estas cartas distan mucho de ser a las que tendría acceso un espía que solo hubiera ido a Lisboa a informarse sobre los Descubrimientos y a extraer un mapa. Cantino era un invitado de honor en la corte lusa como representante de Ercole I d'Este, donde tenía la protección de Don Manuel I. Podría ser, por tanto, que Alberto Cantino no tuviera que sustraer el Planisferio sobornando, engañando o intrigando, sino que pudo tener permiso de los monarcas portugueses para obtenerlo valiéndose de la condición de embajador con la que llegó a Lisboa y las buenas relaciones que unían Portugal y Ferrara; esto explicaría la facilidad con la que un personaje tan distinguido y reconocido pudo extraer de la celosa capital do sigilo semejante documento cartográfico.

Por otro lado, a Cantino -y, consecuentemente, al duque- parecen interesarle más aspectos relacionados con las cortes europeas y con el modus vivendi de las altas esferas de la Lisboa de la época que lo referente a la supuesta misión que tendría Cantino. Lo que también parece interesarle mucho son los movimientos del embajador veneciano, Pasqualigo, al cual cita repetidas veces en las cartas; polos opuestos en una tirante relación que se remonta al último tercio del siglo XV, Ferrara y Venecia coinciden también en Lisboa, lo que, a nuestro parecer, es una casualidad bastante improbable. Al juego se suma Portugal, blanco de los recelos venecianos por su comercio con las Indias y con contactos casi continuos con Ferrara durante el siglo XV, como ha sido expuesto en este estudio. Ciertamente, pocas son las coincidencias que en la Historia pueden contarse, y esta, a la luz de las palabras de Cantino, no podría ser una de ellas.

\section{Referencias Bibliográficas}

ARCINIEGAS, Germán. Why America?: 500 Years of a Name: The Life and Times of Amerigo Vespucci. Bogotá: Villegas Asociados, 2002.

BALLESTEROS BERETTA, Antonio. La marina cántabra. I, De sus orígenes al siglo XVI. Santander: Excma. Diputación Provincial de Santander, 1968.

BARROS, João de. Primeira decada da Asia [en línea]. Lisboa: Aillaud, [1552] 1920. Disponible en $<$ http://archive.org/details/primeiradecadada00barr $>$.

\footnotetext{
${ }^{85}$ OLIVEIRA E COSTA, João Paulo. D. Manuel I (1469-1521). En: Enciclopedia Virtual da Expansão Portuguesa [em línea]. Lisboa: CHAM, s.f. disponible em $<$ http://eve.fcsh.unl.pt/content.php?printconceito $=921>$.
} 
BETANZOS, Miguel. Americo Vespucio. Buenos Aires: Penguin Random House Grupo Editorial Argentina, 2012.

BROTTON, Jerry. Historia del mundo en 12 mapas. Barcelona: Debate, 2014.

BROWN, Rawdon (ed.). Calendar of State Papers and Manuscripts Relating, to English Affairs, Existing in the Archives and Collections of Venice: And in Other Libraries of Northern Italy. London: H. M. Stationery office, 1867.

CAMPANA, Cesare y CAMPANA, Agostino. Supplimento All'Historia Della Vita Del Catolico Re delle Spagne, D. Filippo II. d' Austria; Cioè Compendio di quanto nel mondo è avvenuto dall'anno 1583 fino al 1596 D'Agostino Campana Et Historia Universale di quant' è occorso dal 1596 fino al 1599 Di Cesare Campana Aquilano, vol. V. Venecia: Apresso Bartolomeo Carampello, 1609.

CANTINO, Alberto, PEREIRA, Gabriel y CANTO, Eugénio do (eds.). Carta d'Alberto Cantino, de 1501 ao Duque de Ferrara. Lisboa: Imp. Nacional, 1909.

CANTINO, Alberto; HARRISE, Henry y ALMEIDA, Frederico de (eds). Document inédit concernant Vasco da Gama: relation adressée a Hercule d'Este, Duc de Ferrare. Paris: 1889.

CATTANEO, Angelo. Portugal e Cidades Italianas (s.XIV-XVI). Enciclopedia Virtual da Expansão Portuguesa [en línea]. Lisboa: CHAM, s.f. Disponible en $<$ http://eve.fcsh.unl.pt/content.php?printconceito=1191>.

CERRO BEX, Victoriano del. Itinerario seguido por Felipe I el Hermoso en sus dos viajes a España. Chronica Nova. 1973, n. VIII.

CHIPMAN, Donald E. Nuño de Guzmán y la provincia de Pánuco en Nueva España. Tamaulipas: CIESAS, 2007.

COMMIRE, Anne y KLEZMER, Deborah. Women in World History: Gab-Harp. Open Library: Yorkin Publications, 1999.

CORDEIRO, Luciano. A senhora duqueza. Lisboa: Livraria Ferin, 1889.

CORREIA, Gaspar y DE LIMA FELNER, Rodrigo José (eds.). Lendas da India. Lisboa: Typ. da Academia Real das Sciencias, 1864.

CORTESÃO, Armando y TEIXEIRA DA MOTA, Avelino. Portugaliae monumenta cartographica. Lisboa: Imprenta Nacional-Casa da Moeda, 1987.

CORTESÃO, Armando. Esparsos. Volume I. Coimbra: Universidade Coimbre, 1975.

DE LA SERNA, Juan. Diccionario geográfico, ò descripción de todos los Reynos... Madrid: Imp. de Joachim Ibarra, 1763. 
DE TORRES, Diego. Relación del origen y suceso de los Xarifes y del estado de los reinos de Marruecos, Fez y Tarudante. Madrid: Siglo Veintiuno, 1980.

ELBL, Ivana y ELBL, Martin Malcolm. The Private Archive (Carteggio) of Abbot Dom Fr. Gomes Eanes (Badia Di Firenze) -- An Analytical Catalogue, with Commentary, of Codex Ashburnham 1792 (Biblioteca Medicea Laurenziana, Florence): Part One. Portuguese Studies Review. 2014, vol. 21.

ESTEVES PINHEIRO, José Julio. Carta do Achamento do Brasil de Pêro Vaz de Caminha. ESEG Investigaçao. 2008, n. 7.

FALL, Yoro K. Las cartas de rumbos y su utilización en los siglos XIV y XV (1). Revista de Indias. 1983, n. XLIII.

FERNÁNDEZ-ARMESTO, Felipe. Amerigo. The man who gave his name to América. London: Weidenfeld \& Nicholson, 2006.

FONTOURA COSTA, Abel. Cartas das Ilhas de Cabo Verde de Valentim Fernandes, 1506-1508. Aveiro: Divisao de Publicacoes e Biblioteca da Agencia Geral das Colonias, 1939.

FURTADO, Peter. History's Daybook: A History of the World in 366 Quotations. Londres: Atlantic Books Ltd, 2012.

GARCÍA COBO, Pedro Luis [et al.]. Juan de la Cosa, santoñés universal. Santoña: Excmo. Ayuntamiento de Santoña, Concejalía de Cultura y Deporte, 2000.

GIUSTINIANI, Sebastiano. Four Years at the Court of Henry VIII. London: Imp. Smith, Elder \& Co., 1854.

GOULD, Alice B. Nueva lista documentada de los tripulantes de Colón en 1492. Madrid: Real Academia de la Historia, 1984.

GRAVES, Michael A. R. Henry VIII: A Study in Kingship. Hong Kong: Pearson Education, 2003.

GREENLEE, William B. The Voyage of Pedro Alvares Cabral to Brazil an India. Londres, 1937.

IRVING, Washington. Viajes y descubrimientos de los compañeros de Colon. Madrid: Gaspar y Roig, 1854.

LADERO QUESADA, Manuel Fernando. Recibir princesas y enterrar reinas (Zamora 1501 y 1504). Espacio Tiempo y Forma [en línea]. 2000, n. 13. Disponible en $<$ http://revistas.uned.es/index.php/ETFIII/article/view/3656>. 
LAGUARDA TRÍAS, Rolando A. El predescubrimiento del Río de la Plata por la expedición portuguesa de 1511-1512. Lisboa: Junta de Investigaçoes do Ultramar, 1978.

LESTER, Charles Edwards y FOSTER, Andrew. The Life and Voyages of Americus Vespucius: With Illustrations Concerning the Navigator, and the Discovery of the New World. New York: Baker \& Scribner, 1846.

LEVILLIER, Roberto. América la Bien Llamada. Michigan: Editorial G. Kraft, 1948.

LOPES DE CASTANHEDA, Fernão. Historia do descobrimento e conqvista da India pelos Portvgveses. Lisboa: Typographia Rollandiana, 1833.

LÓPEZ FORERO, Abel Ignacio. Europa en la época del descubrimiento: comercio y expansión ibérica hacia ultramar, 1450-1550. Bogotá: Planeta Colombiana Editorial, 1998.

LOURENÇO FERNANDES, Fernando. O Planisferio de Cantino e o Brasil. Lisboa: Academia de Marinha, 2003.

MAGNAGHI, Alberto. Amerigo Vespucci: studio critico, con speciale riguardo ad una nuova valutazione delle fonti e con documenti inediti tratti dal Codice Vaglienti (Riccardiano 1910). 2 voll. Roma: A.G.A.R, 1924.

MARQUÉS DE OLIVEIRA, Julieta Teixeira. Veneza e Portugal no século XVI. Vol. I. Lisboa: Biblioteca Nacional de Portugal, 1994.

MILANO, Ernesto. Carta del Cantino: All' Edizione in Facsímile. Módena: II Bulino, 2004.

NAVARRETE, Martin Fernández de. Colección de los viages y descubrimientos que hicieron por mar los españoles desde fines del siglo XV. Vol. IV. Madrid: Imprenta Nacional, 1837.

NAVARRETE, Martín Fernández de. Colección de los viages y descubrimientos que hicieron por mar los españoles, desde fines del siglo XV, con varios documentos inéditos concernientes a la historia de la marina castellana y de los establecimientos españoles en India. Madrid: Imprenta Nacional, 1829.

OLIVEIRA E COSTA, João Paulo. D. Manuel I (1469-1521). En: Enciclopedia Virtual da Expansão Portuguesa [em línea]. Lisboa: CHAM, s.f. disponible em $<$ http://eve.fcsh.unl.pt/content.php?printconceito=921>.

PADE, Marianne; PETERSEN, Lene Waage y QUARTA, Daniela. Court of Ferrara \& its patronage. Copenhague: Museum Tusculanum Press, 1990.

PALACIO RAMOS, Rafael. Juan de la Cosa y la época de los descubrimientos: Palacio de Manzanedo, Santoña, 2 de julio-31 de agosto de 2010. Madrid: Sociedad Estatal de Conmemoraciones Culturales, 2010. 
PERAGALLO, Prospero [et al.]. Carta de el-rei D. Manuel ao rei catholico narrandoIhe as viagens portuguezas à India desde 1500 até 1505; reimpressa sobre 0 prototypo romano de 1505, vertida em linguagem e anotada por Prospero Peragallo: seguem em appendice a relação analoga de Lunario Cha Masser e dois documentos de Cantino e Pasqualigo. Lisboa: Typographia da Academia Real das Sciencias, 1892.

PIEL, Joseph M. Livro dos Oficios de Marco Tullio Ciceram, o qual Tornou em Linguagem o Infante D. Pedro, Duque de Coimbra. Coimbra: Universidade de Coimbra, 1948.

POHL, Frederick Julius. Amerigo Vespucci: Pilot Major. London: Routledge, 1966.

PRESTAGE, Edgar. Descobridores portugueses. Lisboa: Edições da 1a Exposição Colonial, 1934.

PUENTE Y OLEA, Manuel de. Los trabajos geográficos de la Casa de Contratación. Sevilla: Escuela Tipográfica y Librería Salesianas, 1900.

RADULET, Carmen M. Os descobrimentos portugueses e a Itália. Lisboa: Vega, 1991.

Real Academia de la Historia (Spain) (ed.). Congreso de Historia del Descubrimiento (1492-1556): actas (ponencias y communicaciones). Madrid: Real Academia de la Historia, 1992.

RIBEIRO, Darcy; ARAÚJO MOREIRA, Carlos de y ARAÚJO MOREIRA, Gisele Jacon de. La fundación de Brasil: testimonios 1500-1700. Venezuela: Fundacion Biblioteca Ayacucho, 1992.

ROGERS, Francis M. y SANTO ESTEVÃO, Gomes de. The Travels of the Infante Dom Pedro of Portugal. Harvard: Harvard University Press, 1961.

ROSENBERG, Charles M. 'Per il bene di...nostra cipta': Borso d'Este and the Certosa of Ferrara. Renaissance Quarterly. 1976, vol. 29, n. 3.

SÁNCHEZ MARTíNEZ, Antonio. La espada, la cruz y el Padrón: soberanía, fe y representación cartográfica en el mundo ibérico bajo la Monarquía Hispánica, 1503-1598. Madrid: Consejo Superior de Investigaciones Científicas, 2013.

SANTA CRUZ, Alonso de. Libro de las Longitudes y manera que hasta agora se ha tenido en el arte de navegar con sus demostraciones y ejemplos, dirigido al muy alto y muy poderoso señor Don Philipe II de este nombre Rey de España. Sevilla: Tip. Zarzuela, [1555] 1921.

SANTO ESTEVÃO, Gomes de. Livro do infante Dom Pedro de Portugal, o qual andou as sete partidas do mundo. Lisboa: Imp. de Francisco Borges de Sousa, 1767. 
SOLER, Isabel. El sueño del Rey. Barcelona: Acantilado, 2015.

SOLER SALCEDO, Juan Miguel. Nobleza española: grandeza inmemorial, 1520. Madrid: Editorial Visión Libros, 2008.

SULLIVAN, Kathryn Amanda. Borso D'Este and the Arthurian Legend: a reconsideration of the Hall of the months in the Palazzo Schifanoia, Ferrara. Birmingham: University of Alabama Press, 2009.

TASSI, Ildefonso. Ludovico Barbo (1381-1443). Roma: Ed. di Storia e Letteratura, 1952.

TUOHY, Thomas. Herculean Ferrara: Ercole D'Este (1471-1505) and the Invention of a Ducal Capital. Cambridge: Cambridge University Press, 2002.

VARIOS, Sociedad V Centenario del Tratado de Tordesillas, y Comissão Nacional para as Comemorações dos Descobrimentos Portugueses (eds.). La Paz y la Guerra en la época del Tratado de Tordesillas. Madrid: Electa España, 1994.

VEGA I PAGÁN, Ernesto. El Almirante: la extraordinaria saga de Cristóbal Colón. Caracas: Presidencia de la República de Venezuela, 1993.

VELILLA TALAVERA, María Margarita (ed.). Aportes de Benjamin Velilla a la Historia del Paraguay. Asunción: Ediciones y Arte S.A., 2005.

VERLINDEN, Charles y PÉREZ-EMBID, Florentino. Cristóbal Colón y el descubrimiento de América. Madrid: Ediciones Rialp, 2006.

\section{Apéndice documental}

Apéndice 1: Carta de Alberto Cantino a Ercole I d'Este, datada a día 30 de enero de 1501.

Al ilustrísimo Hercule d'Este, duque de Ferrara, a Ferrara. Ilustrísimo Príncipe y Excelentísimo Duque, mi maestro y señor por quien tengo el más profundo respeto: un buen correo que partió para el país?, [con él] yo he querido remitir brevemente a Vuestra Excelencia las nuevas noticias en mi otra carta de este mes. Hoy, 30 de enero de 1501, en la catedral, el Serenísimo Rey de Portugal ha nombrado Almirante de las Indias a un tal Don Vasco. En diez días, con doce navíos bien equipados y bien armados, debe ponerse en marcha hacia aquella parte del mundo y bloquear la entrada del Mar Rojo con el fin de que las empresas del Sultán que van de la Meca a Calicut no puedan pasar. El rey Manuel no quiere lidiar con ninguna otra soberanía ni navíos en esos mares, aunque le dijo al embajador veneciano que, si ese año sus negocios no eran prósperos, como se cree, abandonaría la empresa [oriental], ya que el año pasado sus pérdidas ascendieron a 80,000 ducados. No debo olvidar describir la ceremonia que tuvo ocasión con motivo del nombramiento del susodicho almirante. Al principio el soberano entró a la misa con gran pompa, y, una vez hubo concluido la celebración, el susodicho Vasco [que] portaba una hopalanda [turcha?] de satén carmesí a la francesa con doble de armiño, con una boina [breta pour bereta?] así 
como una túnica acorde a la prenda y embellecida con un collar de oro, se situó junto al rey, que estaba rodeado por toda su corte. Un señor avanzó hasta el medio del grupo e hizo una arenga elogiando la grandeza y las virtudes del SeñorRey, hasta el punto de que en todas las partes de su discurso se exaltaba su gloria por encima de la de Alejandro Magno. Después, volviéndose hacia el Almirante, pronunció abundantes palabras de elogio para él y sus antepasados, recordando que por su genio y valor había descubierto toda esta parte de la India. Una vez terminada la oración, el heraldo de armas presentó un libro en su mano y hizo jurar al susodicho Don Vasco fidelidad eterna al rey y a sus descendientes. Luego se arrodilló ante el príncipe, que se quitó un anillo de su mano y se lo colocó [a Vasco] en el dedo. Tras esto se le entregó una espada desnuda al Almirante arrodillado. La tomó con la mano derecha y recogió el estandarte con la mano izquierda. Hecho esto, se encontró besando la mano del rey, como hicieron todos los señores y gentilhombres, regocijándose [el rey] por los honores y dignidades que añadió a su corona, y el embajador de Venecia actuó de la misma manera. Finalmente, la ceremonia se clausuró con una excelente pieza musical.

La majestad el Rey de España ha eliminado por completo ${ }^{86}$ a Gibeltaro, duque de Sibila, y le exige también algo de dinero y otras cosas, por lo que este Rey de Portugal a petición del duque de Braganza, yerno del citado Duque de Sibila, ha mandado al referido Rey de España embajadores para tratar que les sean restituidas sus tierras. El archiduque de Borgoña con 1500 caballos se encuentra en este momento en Burgos con su esposa, a la que acompañan un centenar de damas de honor, todas sobre Chinee bianche? con tanta pompa que es cosa admirable. Se dice que el Rey, que está ahora en Sibilla, lo va a recibir en Córdoba; algunos dicen que en Sibillia, aunque ciertamente por toda España, se preparan fiestas de triomphi inextimabili: espero, tal día, poder dar informaciones completas a V. Ex. a la cual como humilde servidor siempre me dirijo.

Aún como humilde servidor, me dirijo a Su Excelencia. Lisboa, este treinta de enero de 1501. Alberto Cantino ${ }^{87}$.

Apéndice 2: Carta de Alberto Cantino a Ercole I d'Este, datada a día 19 de julio de 1501.

En la colone de Galicia son reunidas algunas naces enviadas por el Rey de Inglaterra para llevar a hija del Rey de España, prometida al príncipe de Inglaterra. Y así la majestad de este Reino de España con grandes naves y gran honor la envía, y en el citado grupo se embarca.

En los últimos días estuvo/e en Sibilla, y vi(o) arder cincuenta y cuatro hombres, los cuales profesaban la fe herética, y decían que una bellísima joven de veinticinco años de la tierra propia era divina y la adoraban, y esa joven era docta y conocía la ley de Moisés. Y [...] de la misma muerte que murieron [los otros] murió ella. [...]

\footnotetext{
${ }^{86} \mathrm{~N}$. del A.: Se interpreta sobre esta cuestión que lo que puede referir el texto es la caída en desgracia del duque, desposeyéndole de sus tierras.

${ }^{87}$ Traducción libre del autor sobre la realizada por Henry Harrise en su edición del texto (primer párrafo). Traducción libre del autor desde el documento original (segundo párrafo). CANTINO, Alberto; HARRISE, Henry y ALMEIDA, Frederico de (eds). Document inédit concernant Vasco da Gama: relation adressée a Hercule d'Este, Duc de Ferrare. Paris: 1889, pp. 18-21.
} 
Solo tengo eso para Vuestra Excelencia. [...] Día 19. Julio. 1501. Servus Alberto Cantino scripsit ${ }^{88}$.

Apéndice 3. Carta de Alberto Cantino a Ercole I d'Este, datada a día 17 de octubre de 1501.

El día cinco del presente [mes] llegó al puerto de Calice una carabela de la majestad del Rey de España, la cual había mandado hace algunos meses a su isla Antilla, y ha traído, sesenta esclavos [...]. No son muy gruesos y no lucen inteligentes, pero tan pronto como sea posible tranno columbino?

Aquella hija del Rey de España, la que iba al encuentro del príncipe de Inglaterra, fue con sus naves al Canal de Fiandra, y tuvo grandísima fortuna, porque todas llegaron a puerto, y solo aquella de la princesa no pudo volver a botarse ${ }^{89}$, que fue maltratada por fortísima tormenta y vientos, y fue devuelta sin el mástil principal ${ }^{90}$ y sin vela a un puerto llamado Redo, que se encuentra entre Bischaglia y la Gallicia.

Y allí, por el miedo y el tormento sufrido enfermó de fiebre, y no quiso salir de la nave. Cuando el rey de Inglaterra supo de tal fortuna, rápidamente envió cuatro naves, y hallándola en el citado lugar, la hicieron montar en su nave, y con buen viento en seis días llegaron a Premua ${ }^{91}$, que está en Cornovalia [Cornualles], y allí fue recibida con grandes honores. Así que uno, el cual en poquísimos días ha llevado al Rey a la Reina esta noticia, ha recibido como recompensa de la reina cien ducados de oro.

Hoy hace quince días que el Rey nos invitó al embajador de Venecia y a mí a recorrer y ver uno de sus palacios, llamado Sintra, a 15 milia de Lisboa, el cual recorrimos a voluntad, y durante cuatro días fuimos recibidos con gran caza? y placer por un Seschaldo del Rey. La condición del mismo quiero relatar a V. Ex. en la medida de lo posible. Este palacio está situado sobre una bella colina y en la parte de delante tiene un cinturón de altísimas montañas de cuatro vientos, es decir, la cubre desde el Greccho de Levante a Sirocho y Medozi, y por este motivo siempre hace frío allí. Desde la parte posterior, es decir, por cuanto se extiende hasta la Bechie, Ponente, Maestro y Tramontana, todo son grandes y abiertas llanuras, y muestra también el mar océano. En torno a tres millas de aquella valada están los jardines con frutos [...] en grandes cantidades, y por el medio los mismos corre un placentero riachuelo; es esto todo cuanto puedo decir del sitio el cual es realmente maravilloso, pero queriendo también describir la parte de las habitaciones, habrá sido necesario un gran arquitecto. [Parece] como si cada habitación y cada estancia estuvieran exentas de las otras [il suo coperto] y todas están en un conjunto compacto pero no juntas, insisto, en lo que no encuentro sentido alguno.

\footnotetext{
${ }^{88}$ Ibídem, pp. 35-36.

${ }^{89} \mathrm{~N}$. del A.: El verbo firmarse que aparece en el documento original resulta difícil de traducir en este contexto. Considerando el dicho contexto, la opción elegida parece la más apropiada.

${ }_{90} \mathrm{~N}$. del A.: Nuevamente el contexto nos obliga a buscar la traducción más correcta para larboro grande.

91 En: CANTINO, Alberto; HARRISE, Henry y ALMEIDA, Frederico de (eds). Document inédit... Op. cit., p. 34, el editor anota [sic pro Plymouth] junto a Premua.
} 
Pero la abundancia de oro, en los solari con sutil artificio trabajados, y las piedras vidriadas colocadas forrando los muros y per selegate in terra hacen de ellas algo bellísimo para quien las contempla. De lo alto de una de esas cuatro montañas viene conducida una corriente de agua, la cual, aunque hace cuatro bellas fuentes en ciertos patios, para casi en cada habitación y lugar conducida a través de mármol por el cual va siempre corriendo, de modo que para todos es accesible el agua, ni baña ni se expande, sino que [está ahí] cuanto place al hombre: pero en cada lugar el oro es oro, y sin querer dejarme llevar por pasión alguna diré que el palacio en si mismo no es comparable en cosa alguna a la gloria de Belguardo, y por esto quería escribir a V. Ex., [...] porque este rey se preocupa por la fastuosidad y fama [de su palacio], y ya ha oído hablar de Belguardo por su fama, y como sabe alguien que lo ha visto siempre tiene en su ánimo hacer comparaciones; pero ciertamente, sin adulación alguna así como raro o ninguno es el príncipe que se aproxima a V.S [en la posesión] de bellas tierras y edificaciones, así también no tienen la virtud a la real presencia, costumbre y magnanimidad de V. Ex., la cual queriendo confesar mi ignorancia, digo no haberlo sabido si no hubiera visto y practicado otras cortes, Reyes y Señores. Así, siempre mantengo tu reputación favorable y saludable y los convenzo de tu gracia plena, tal y como deseáis. Vi en Sintra algo excelente que no quiero omitir. Era una columnata de Diaspese, de cuatro pies de largo y gruesa como una botta de octo mastelli et meglio ${ }^{92}$, la cual el rey hacía serrar en tablas de un grosor de dos dedos [luna] ? ${ }^{93}$, y eran ocho meses que siempre dicha noche se trabajaba ni una spana? y media, y en todo este tiempo tuvieron fortuna [o infortunio] ${ }^{94}$.

Han pasado cuarenta días desde que los moros en la frontera de la tierra que tiene este Rey en África se levantaran con cerca de treinta gentilhombres al frente, los cuales este Rey ha estado de muy mal humor [los días], pero ahora los soldados que allí tiene el Rey han tomado cerca de trescientos moros, lo que en esta tierra [Portugal] ha despertado gran alegría. Introduzco un decreto que ha puesto en uso este Rey. Todos aquellos que en su reino cometan acto alguno merecedor de severo castigo, los que asesinen, todos aquellos que roben [...], con el tiempo serán enviados a estos lugares e islas y les será impuesto lo siguiente: que si alguna vez volvieran de donde los desterraron por tierra a Lisboa, se les perdonará el delito y se les concederá la merced de quinientos ducados de oro; pero creo yo que raro sería tal regreso, aunque hay un lugar que se llama Santa Cruz, por ser optimista, abundante de dulcísimos frutos y buen aire, donde cinco marineros huyeron de la nave del Rey y decidieron quedarse allí.

Me dirijo a V. Ex. Lisboa, día 17 de octubre de $1501^{95}$.

\footnotetext{
${ }^{92} \mathrm{~N}$. del A.: Unidad de medida relacionada con el grosor de tinas, cubas o toneles.

${ }^{93} \mathrm{~N}$. del. A.: Fragmento de gran complejidad que probablemente se trate de algún juego de palabras o alusión metafórica. La traducción es imperfecta.

${ }^{94} \mathrm{~N}$. del A.: Nuevamente, las dificultades de transcripción e interpretación de la palabra sighato dificultan una buena traducción. Por el contexto, se considera más coherente la palabra fortuna.

${ }_{95}$ CANTINO, Alberto, PEREIRA, Gabriel y CANTO, Eugénio do (eds.). Carta d'Alberto Cantino, de 1501 ao Duque de Ferrara. Lisboa: Imp. Nacional, 1909.
} 